\title{
Combined Dust Detection Algorithm for Asian Dust Events Over East Asia Using GK2A/AMI: a Case Study in October 2019
}

\author{
Jae-Cheol Jang ${ }^{1} \cdot$ Soobong Lee ${ }^{1}$ (D) Eun-Ha Sohn ${ }^{1} \cdot$ Yoo-Jeong Noh ${ }^{2} \cdot$ Steven D. Miller ${ }^{2}$
}

Received: 29 June 2020 / Revised: 8 February 2021 / Accepted: 16 February 2021 / Published online: 7 April 2021

(C) The Author(s) 2021

\begin{abstract}
A combined algorithm comprising multiple dust detection methods was developed using infrared (IR) channels onboard the GEOstationary Korea Multi-Purpose SATellite 2A equipped with the Advanced Meteorological Imager (GK2A/AMI). Six cloud tests using brightness temperature difference (BTD) were utilized to reduce errors caused by clouds. For detecting dust storms, three standard BTD tests (i.e., $B T_{12.3}-B T_{10.5}, B T_{8.7}-B T_{10.5}$, and $B T_{11.2}-B T_{10.5}$ ) were combined with the polarized optical depth index (PODI). The combined algorithm normalizes the indices for cloud and dust detection, and adopts weighted combinations of dust tests depending on the observation time (day/night) and surface type (land/sea). The dust detection results were produced as quantitative confidence factors and displayed as false color imagery, applying a dynamic enhancement background reduction algorithm (DEBRA). The combined dust detection algorithm was qualitatively assessed by comparing it with dust RGB imageries and ground-based lidar data. The combined algorithm especially improved the discontinuity in weak dust advection to the sea and considerably reduced false alarms as compared to previous dust monitoring methods. For quantitative validation, we used aerosol optical thickness (AOT) and fine mode fraction (FMF) derived from low Earth orbit (LEO) satellites in daytime. For both severe and weakened dust cases, the probability of detection (POD) ranged from 0.667 to 0.850 and it indicated that the combined algorithm detects more potential dust pixels than other satellites. In particular, the combined algorithm was advantageous in detecting weak dust storms passing over the warm and humid Yellow Sea with low dust height and small AOT.
\end{abstract}

Keywords GK2A/AMI · Asian dust · Dust detection · Combined algorithm

\section{Introduction}

Asian dust, lofted from the Gobi and Taklamakan deserts of China and Mongolia, is one of the major pollutant species adversely impacting air quality across the whole of East Asia, including the Korean Peninsula (Wang et al. 2008a). Strong winds under dry weather conditions carry away fine sand particles from their arid and semi-arid regions. Via the compounding effects of saltation, these sands loft additional

Responsible Editor: Myoung Hwan Ahn.

Soobong Lee

sblee88@korea.kr

1 National Meteorological Satellite Center, Korea Meteorological Administration, 64-18, Guam-gil, Gwanghyewon-myeon, Jincheon-gun, Chungcheongbuk-do 27803, Republic of Korea

2 Cooperative Institute for Research in the Atmosphere (CIRA), Colorado State University, Fort Collins, CO 80523, USA particles into the atmosphere, subsequently spreading out over surrounding areas. The incipient dust storms can result in severe degradation of air quality and visibility (Wang et al. 2008b). Although dust storms increase marine biological productivity by adding iron-rich metals to the ocean, they have a significant influence on regional climate, which occurs due to the change in the Earth's radiation balance (Seinfeld et al. 2004; Tan and Wang 2014). The frequency of dust events affecting the Korean Peninsula has increased significantly since the 2000 s, thereby the importance of Asian dust monitoring was emphasized (Kurosaki and Mikami 2003; Kim 2008).

Since in-situ measurements with high accuracy and precision are point observations, they have limitation for monitoring the detailed spatial distribution of a dust storm (Lei and Wang 2014). Satellite-based remote sensing is necessary for addressing the limitations of in-situ measurements. Several techniques were developed based on various contemporary satellite sensors such as the National Oceanic and Atmospheric Administration (NOAA) Advanced Very HighResolution Radiometer (AVHRR), Suomi National Polar- 
orbiting Partnership (NPP) Visible Infrared Imaging Radiometer Suite (VIIRS), Terra/Aqua Moderate Resolution Imaging Spectroradiometer (MODIS), Himawari-8/9 Advanced Himawari Imager (AHI), and the Geostationary Operational Environmental Satellite-R series Advanced Baseline Imager (GOES-R/ABI) (Iino et al. 2004; Miller et al. 2017; Zhang et al. 2018). Since these geostationary (GEO) satellites have finer temporal resolution than low Earth orbit (LEO) satellites, they are considered more advantageous for monitoring the rapid evolution and advection of dust storms (Wang et al. 2003; Li et al. 2007). However, the dust detection methods in previous studies were optimized for LEO satellites, and, thus, to obtain good performance for dust monitoring from GEO satellites it is necessary to improve the quality of the dust detection algorithm used for GEO satellites.

Due to 24-hr availability of IR channels, the importance of dust detection based on IR channels has been emphasized rather than visible (VIS) channels (Pierangelo et al. 2004). Since IR channel's response to dust is dependent on the size, distribution, composition, and refractive indices of dust particles, it is necessary to use the IR channels to retrieve dust information (Sokolik and Toon 1999; Schepanski et al. 2007). Water vapor absorbs more radiation in the $12 \mu \mathrm{m}$ channel than the $11 \mu \mathrm{m}$ channel; however, the emissivity of dust near the $11 \mu \mathrm{m}$ channel is lower than the $12 \mu m$ channel (Shenk and Curran 1974). Additionally, the emissivity of dust increased with particle size near the $11 \mu \mathrm{m}$ channel, whereas near the $8.6 \mu \mathrm{m}$ channel, the emissivity of dust was low (Salisbury and Eastes 1985; Salisbury and Wald 1992). As satellite channels had been increasing, it was possible to apply the additional brightness temperature difference (BTD) methods using an $8.6 \mu \mathrm{m}$ channel (Roskovensky and Liou 2005; Hansell et al. 2007).

Although BTD methods are advantageous for dust monitoring, they present numerous challenges. Spectral characteristics of lofted dust were often found to be similar to the spectral properties of the dust source regions depending on environmental conditions (Ashpole and Washington 2012; Liu et al. 2013). Furthermore, since the performance and the thresholds of BTD methods depend on the dust event, simultaneously using the several methods has been recommended (Baddock et al. 2009). Accordingly, techniques for combining the multiple dust detection methods and displaying the combined dust detection algorithm have been proposed (Park et al. 2014; Miller et al. 2017). Since these combined algorithms also used the BTD methods, uncertainty of the BTD methods based on error factors (i.e., thin clouds, low-altitude clouds, dust source regions) is still present. Nevertheless, the combined dust detection algorithm is considered to improve the accuracy of dust detection by complementing the disadvantages of each method.

The National Meteorological Satellite Center (NMSC) of the Korean Meteorological Administration (KMA) has monitored Asian dust that affects the Korean Peninsula using insitu measurements and remote sensing. Korea's first GEO meteorological satellite, the Communication, Ocean, and Meteorological Satellite (COMS), equipped with the Meteorological Imager (MI), was launched on 26 June 2010. COMS/MI had $10 \mu m$ and $12 \mu m$ channels and used the BTD method to monitor the dust events. As the GEOstationary Korea Multi-Purpose SATellite 2A (GEO-KOMPSAT 2A, GK2A) was launched on 4 December 2018, it became possible to use the $8.7 \mu \mathrm{m}$ channel and continuously monitor dust storms throughout the day. As GK2A has more channels than COMS/MI, including an $8.6 \mu \mathrm{m}$ channel, it is expected to monitor dust storms with better performance.

Thus, KMA forecasters have primarily used dust RGB imagery for dust monitoring. Furthermore, the current dust RGB imagery is based on the recipe of the European Organization for the Exploitation of Meteorological Satellites (EUMETSAT) (Moreira 2011). By using the dust RGB product from GEO satellites, it is possible to detect dust movement by identifying continuous variations in the dust signal. However, the dust RGB product, composed of the BTD using the $8.7 \mu m, 11 \mu m$, and $12 \mu m$ channels, can lead to confusion as some of the surface and cloud features produce similar colors as the dust storms, which is caused by the diurnal variations of surface temperature and mixed pixels within thin clouds. Therefore, it is necessary to develop a combined algorithm with multiple dust detection methods to reduce the false alarm factors and accurately detect the weaker dust storms.

The Korean Peninsula is affected by dust storms transported from China across the Yellow Sea's warm water and moist air. Typically, when the dust reaches the Korean Peninsula, it spans a layer from the surface up to an altitude of $1-2 \mathrm{~km}$ and is optically thinner than its source region, with aerosol optical thickness (AOT) less than 1. When dust arrives on the Korean Peninsula, its detection is challenging using dust RGB imagery and previous single BTD methods. Therefore, to improve the performance of dust detection, we propose a new dust detection algorithm by combining several cloud and dust tests. This study is organized as follows: Section 2 presents the data used; Section 3 provides an overview of the combined dust detection algorithm and the method is shown as false color imagery proposed by Miller et al. (2017); qualitative validation (against RGB imagery and ground-based lidar data) and quantitative validation (against Suomi-NPP aerosol products) are shown in Section 4; and Section 5 presents a summary and conclusion.

\section{Data}

\subsection{GEO-KOMPSAT 2A (GK2A)}

GK2A, which was launched in 4 December 2018 and has been operated by the KMA NMSC, uses the Advanced Meteorological Imager (AMI). The AMI sensor has four 
VIS channels, two short-wave infrared (SWIR) channels, four mid-wave infrared (MWIR) channels, and six thermal infrared (TIR) channels (Table 1). As GK2A/AMI has IR channels useful for dust detection near $8.7 \mu \mathrm{m}, 11 \mu \mathrm{m}$, and $12 \mu \mathrm{m}$, highly advanced dust detection methods proposed in previous studies can be used (Iino et al. 2004; Zhang et al. 2018). The spatial resolution of the VIS channels is $0.5 \mathrm{~km}$ or $1.0 \mathrm{~km}$ (band dependent), and the spatial resolution of IR channels is $2.0 \mathrm{~km}$ (Table 1). The observation data from GK2A/AMI can be classified into full disk (FD, every $10 \mathrm{~min}$ ), extended local area (ELA, every $2 \mathrm{~min}$ ), and local area (LA, every 2 min) depending on the spatial coverage. Given its high spatial and temporal resolution, GK2A/AMI is more capable of monitoring the onset, transport, and dissipation of dust storms than COMS and other LEO satellites. In this study, we used FD data to monitor the transport of dust storms originating in the deserts of China and Mongolia as they reach the Korean Peninsula.

\subsection{Validation Data}

\subsubsection{Himawari-8}

Himawari-8/AHI, which was launched on 7 October 2014, has been used by the KMA NMSC to provide forecaster guidance since 2017. We used the true color RGB imagery and the dust RGB imagery from Himawari-8/AHI for qualitative validation. The dust RGB imagery was made by referring to the dust RGB recipe based on Meteosat Second Generation (MSG) Spinning Enhanced Visible and Infrared Imager (SEVIRI) developed by
EUMETSAT. The BTD between the $12.3 \mu \mathrm{m}$ and $10.4 \mu \mathrm{m}$ channels is applied for the red (R) component, while the BTD of $10.4 \mu \mathrm{m}$ and $8.6 \mu \mathrm{m}$ channels is applied for the green $(\mathrm{G})$ component (Lensky and Rosenfeld 2008; Banks et al. 2013). The BTD of the $10.4 \mu m$ and $13.3 \mu m$ channels is applied for the blue (B) component for the clear-sky and the high cloud tests, unlike the recipe from MSG SEVIRI (Ganci et al. 2011). As a result, the color of the dust pixels ranges from red to pink and purple. The ability to continuously monitor the progression of a dust storm when using dust RGB imagery from GEO satellites can help overcome some of the color ambiguity in dust RGB imagery. Thus, it is common to use the dust RGB imagery for validation of the spatial distribution of a dust storm (Fuell et al. 2016; Ashpole and Washington 2012; Banks et al. 2013; Miller et al. 2017).

\subsubsection{Suomi-NPP (S-NPP)}

Suomi-NPP (S-NPP) is a LEO satellite launched on October 28, 2011 and has been operated by National Aeronautics and Space Administration (NASA). S-NPP/VIIRS has sixteen moderate resolution bands, five imaging bands, and a daynight band to observe the global environment, and its wavelength ranges from $0.41 \mu \mathrm{m}$ to $12.5 \mu \mathrm{m}$. NASA provides aerosol products based on S-NPP/VIIRS in near real time. For quantitative validation, among the aerosol products, we used the AOT and fine mode fraction (FMF) of aerosol level 2 data (AERDB), which was based on the combination of the Deep Blue (DB) algorithm and Satellite Ocean Aerosol Retrieval (SOAR) algorithm (Sayer et al. 2018a). At nadir,
Table 1 Specifications of the spectral channels of GK2A/AMI

\begin{tabular}{lllll}
\hline Channel No. & Channel Name & $\begin{array}{l}\text { Min of wavelength } \\
(\mu m)\end{array}$ & $\begin{array}{l}\text { Max of wavelength } \\
(\mu m)\end{array}$ & $\begin{array}{l}\text { Resolution } \\
(\mathrm{km} \times \mathrm{km})\end{array}$ \\
\hline 1 & VIS(VIS0.4) & 0.431 & 0.479 & $1.0 \times 1.0$ \\
2 & VIS(VIS0.5) & 0.5025 & 0.5175 & $1.0 \times 1.0$ \\
3 & VIS(VIS0.6) & 0.625 & 0.66 & $0.5 \times 0.5$ \\
4 & VNIR(VIS0.8) & 0.8495 & 0.8705 & $1.0 \times 1.0$ \\
5 & SWIR(NIR1.3) & 1.373 & 1.383 & $2.0 \times 2.0$ \\
6 & SWIR(NIR1.6) & 1.601 & 1.619 & $2.0 \times 2.0$ \\
7 & MWIR(IR3.8) & 3.74 & 3.96 & $2.0 \times 2.0$ \\
8 & MWIR(IR6.3) & 6.061 & 6.425 & $2.0 \times 2.0$ \\
9 & MWIR(IR6.9) & 6.89 & 7.01 & $2.0 \times 2.0$ \\
10 & MWIR(IR7.3) & 7.258 & 7.433 & $2.0 \times 2.0$ \\
11 & TIR(IR8.7) & 8.44 & 8.76 & $2.0 \times 2.0$ \\
12 & TIR(IR9.6) & 9.543 & 9.717 & $2.0 \times 2.0$ \\
13 & TIR(IR10.5) & 10.25 & 10.61 & $2.0 \times 2.0$ \\
14 & TIR(IR11.2) & 11.08 & 11.32 & $2.0 \times 2.0$ \\
15 & TIR(IR12.3) & 12.15 & 12.45 & $2.0 \times 2.0$ \\
16 & TIR(IR13.3) & 13.21 & 13.39 & $2.0 \times 2.0$ \\
\hline
\end{tabular}


AERDB has a spatial resolution of $6 \mathrm{~km}$ and determines atmospheric properties for daytime over cloud-free and snowfree. The AOT is defined as the integral of light extinction by the aerosol in the atmospheric column at $0.55 \mu \mathrm{m}$, and a high AOT means that the atmospheric column of a pixel has a very large amount of aerosol load (Wang et al. 2020). The FMF is defined as the ratio of fine mode AOT to total AOT, and refers to the contribution of fine aerosol to total AOT; a high FMF infers that a pixel is in a fine aerosol (i.e., sulfate and anthropogenic aerosol) dominated condition (Sayer et al. 2018b).

\subsubsection{AD-Net Lidar Data}

The Asian dust and aerosol light detection and ranging (lidar) observation network (AD-Net) is a network of ground-based lidars established to observe the properties of atmospheric aerosols, including dust. The network contributes to the Global Atmospheric Watch (GAW) Aerosol Lidar Observation Network (GALION) operated by World Meteorological Organization (WMO) (Shimizu et al. 2017; Tsedendamba et al. 2019). The standard lidar system of AD-Net is composed of two-wavelength (1064 $\mathrm{nm}$ and $532 \mathrm{~nm}$ ) polarization sensitive Mie-scattering lidars. The data (sourced from https://wwwlidar.nies.go.jp/AD-Net/) are transferred by the National Institute for Environmental Studies, Japan, and 20 stations are operated by specific research institutes (Sugimoto et al. 2008). For qualitative validation, we used data from two stations, Gwanak Seoul (37.46 $\left.{ }^{\circ} \mathrm{N}, 126.95^{\circ} \mathrm{E}\right)$ and Gosan Jeju (33.29 ${ }^{\circ} \mathrm{N}, 126.16^{\circ} \mathrm{E}$ ), located in Korea (Fig. 1). These stations produce the following atmospheric properties every $15 \mathrm{~min}$ : attenuated backscatter coefficient (532 nm and $1064 \mathrm{~nm}$ ), volume depolarization ratio $(532 \mathrm{~nm})$, aerosol extinction coefficient $(532 \mathrm{~nm})$, dust extinction coefficient $(532 \mathrm{~nm})$, spherical particle extinction coefficient $(532 \mathrm{~nm})$, aerosol depolarization ratio $(532 \mathrm{~nm})$, and estimated mixing layer height.

\section{Methodology}

Clouds, whose spectral properties are often similar to dust storms, are a major cause of false alarms in dust detection, and, thus, previous studies have emphasized discriminating dust from clouds (Roskovensky and Liou 2005; Hansell et al. 2007). As the BTDs are often similar among dust storms and cirrus clouds, low thin clouds, and fog, it was essential to eliminate potential false alarms by accurately detecting the clouds. Cloud detection has been investigated using various methods; however, BTD characteristics are significantly affected by surface temperature and surface type (MODIS Cloud Mask Team 2010). Therefore, we combined multiple cloud tests to reduce false alarms, which are described in Section 3.1.

Since the spectral response of a dust storm varies with environmental conditions, the performance and the thresholds of BTD methods depend on the dust event. Thus, it is difficult to detect the dust via the binary product (dust or non-dust), and simultaneously using several methods has been recommended (Baddock et al. 2009). When combined dust test is used, it is possible to solve drawbacks of the binary product and retrieve continuous dust detection products in diverse meteorological conditions, which are described in Section 3.2.

In the proposed algorithm, unlike the binary products, we calculate the continuous cloud detection $(C D)$ and dust detection $(D D)$ parameters, which range from 0.0 (confident clear-sky or non-dust) to 1.0 (confident cloudy or dust), by applying a normalization, as shown in Eq. 1. A similar normalization approach was used by Miller et al. (2017) in the Dynamic Enhancement Background Reduction Algorithm (DEBRA), thereby suggesting that normalized parameters can improve the accuracy of dust monitoring to suppress the abnormal and irregular sharp gradients. A general form of each normalized parameter is defined as follows:

$N_{x}=\frac{x-M I N_{x}}{M A X_{x}-M I N_{x}}$

where $N_{x}$ indicates the normalized index of parameter $x$, and $M I N_{x}$ and $M A X_{x}$ represent the minimum value (MIN) and maximum value (MAX) of parameter $x$, respectively. Not only does each satellite have a different spectral response function and a different center wavelength of channels with respect to data, but also the BTD characteristics vary depending on environmental conditions of dust events (Baddock et al. 2009). Thus, even if the same BTD method was used, it is necessary to retrieve the optimal threshold with respect to the data used and the study area. In this study, empirical thresholds optimized for GK2A/AMI and East Asia were used. When the value of $x$ is below MIN or above MAX, it is truncated to these bounds to ensure the range from 0.0 to 1.0 .

\subsection{Cloud Tests}

For retrieval of the $C D$ parameters, we applied six cloud tests (Fig. 2). First, we defined the BTD test for overall cloud and cold cloud. As the atmospheric window (clean window) channel near $10.5 \mu \mathrm{m}$ is scarcely affected by atmospheric water vapor, it can detect cold clouds based on the background brightness temperature (Key 2002; Frey et al. 2008) as follows:

$C D I 1=1-\frac{B T_{10.5}-M I N_{C D I 1}}{M A X_{C D I 1}-M I N_{C D I 1}}$

where $M A X_{C D I 1}$ is the highest brightness temperature (BT) near $10.5 \mu \mathrm{m}$ during reference periods. When the BT has the highest value during a reference period, we assume that the pixel is in clear-sky. The reference period should be long enough for each pixel to be cloud free at least one day and short enough not to be affected by seasonal variations. Previous studies set the period 
Fig. 1 Map of East Asia including Korea, Russia, Japan, China, and Mongolia. Blue stars and text indicate the locations and names of AD-Net lidar stations

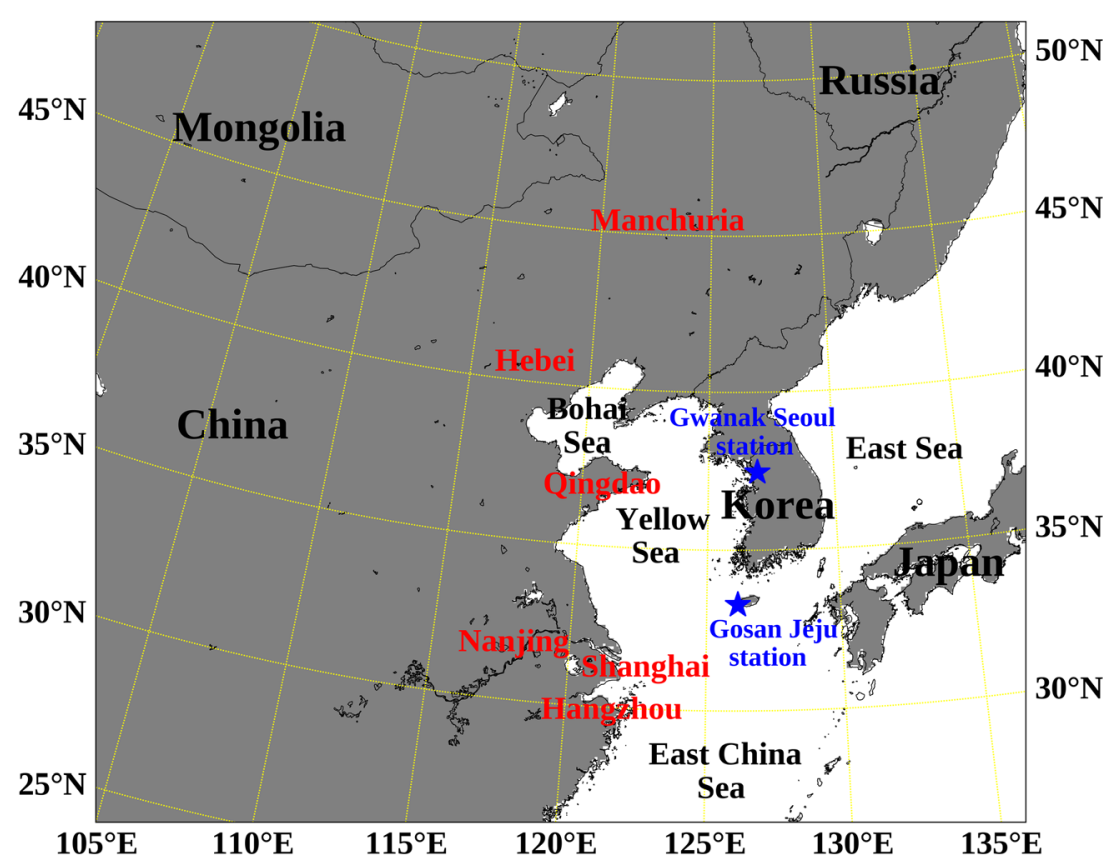

of reference imagery from 10 days to 30 days (Knapp et al. 2005; $\mathrm{Hu}$ et al. 2008; Ashpole and Washington 2012; Liu et al. 2013; Park et al. 2014). Since the lowest bias and rootmean-square errors were produced when using a 14-day window (Knapp et al. 2005), we used a 14-day window for the reference imagery and set $M I N_{C D I 1}$ as $\left(M A X_{C D I 1}-40\right)$.

Next, we defined the 2nd BTD test for thick high clouds and deep convective clouds and used the BTD between the $10.5 \mu \mathrm{m}$ channel and the $6.3 \mu \mathrm{m}$ channel (Schmetz et al. 1997; Miller et al. 2017) as follows:

$C D I 2=\frac{\left(B T_{6.3}-B T_{10.5}\right)-M I N_{C D I 2}}{M A X_{C D I 2}-M I N_{C D I 2}}$

where $M I N_{C D I 2}$ and $M A X_{C D I 2}$ are -25.0 and - 15.0, respectively. We defined the 3rd BTD test for nighttime clouds over a humid surface and used the BTD between the $7.3 \mu \mathrm{m}$ channel and the $8.7 \mu m$ channel (MODIS Cloud Mask Team 2010) as follows:

$C D I 3=\frac{\left(B T_{7.3}-B T_{8.7}\right)-M I N_{C D I 3}}{M A X_{C D I 3}-M I N_{C D I 3}}$

where $M I N_{C D I 3}$ and $M A X_{C D I 3}$ are -11.0 and -5.0 , respectively. We defined the 4th BTD test for clear-sky and used the BTD between the $7.3 \mu \mathrm{m}$ channel and the $10.5 \mu \mathrm{m}$ channel (Liu et al. 2004; Frey et al. 2008) as follows:

$C D I 4=\frac{\left(B T_{7.3}-B T_{10.5}\right)-M I N_{C D I 4}}{M A X_{C D I 4}-M I N_{C D I 4}}$

where $M I N_{C D I 4}$ and $M A X_{C D I 4}$ are -11.0 and -5.0 , respectively. We defined a 5 th BTD test particularly for nighttime clouds over a cold surface and used the BTD between the 6.9 $\mu m$ channel and the $10.5 \mu m$ channel (Ackerman 1996; Liu et al. 2004) as follows:

$C D I 5=\frac{\left(B T_{6.9}-B T_{10.5}\right)-M I N_{C D I 5}}{M A X_{C D I 5}-M I N_{C D I 5}}$

where $M I N_{C D I 5}$ and $M A X_{C D I 5}$ are -15.0 and -9.0, respectively. We defined a 6th BTD test for clear-sky and used the BTD between the $13.3 \mu \mathrm{m}$ channel and the $10.5 \mu \mathrm{m}$ channel (Trepte et al. 2006; Frey et al. 2008) as follows:

$C D I 6=\frac{\left(B T_{13.3}-B T_{10.5}\right)-M I N_{C D I 6}}{M A X_{C D I 6}-M I N_{C D I 6}}$

where $M I N_{C D I 6}$ and $M A X_{C D I 6}$ are -8.0 and -3.0 , respectively.

Using Eq. 2 to Eq. 7, our two combined parameters, $C D I_{\text {com } 1}$ and $C D I_{\text {com } 2}$, are defined as follows:

$C D I_{c o m 1}=\frac{(C D I 1+C D I 2+C D I 3)-M I N_{C D I_{c o m 1}}}{M A X_{C D I_{c o m 1}}-M I N_{C D I_{c o m 1}}}$

$C D I_{\text {com } 2}=\frac{(C D I 4+C D I 5+C D I 6)-M I N_{C D I_{\text {com } 2}}}{M A X_{C D I_{\text {com } 2}}-M I N_{C D I_{\text {com } 2}}}$

where MAX of $C D I_{\text {com } 1}$ and $C D I_{\text {com } 2}$ are 2.1, and MIN of $C D I_{\text {com } 1}$ and $C D I_{\text {com } 2}$ are 0.3 . The final $C D$ parameter is defined as follows:

$C D=\frac{\left(C D I_{c o m 1}+C D I_{c o m 2}\right)-M I N_{C D}}{M A X_{C D}-M I N_{C D}}$

where $M I N_{C D}$ and $M A X_{C D}$ are 0.0 and 1.8 , respectively. 
Fig. 2 Flow diagram of cloud detection for the GK2A/AMI combined dust detection algorithm

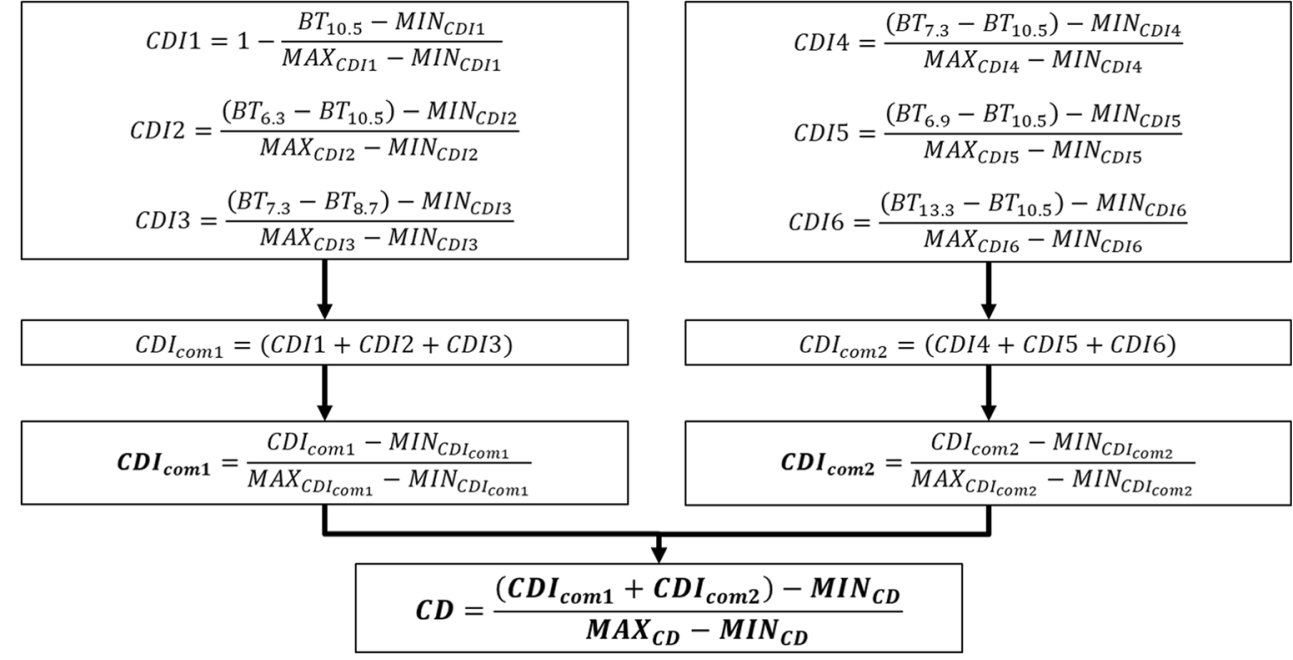

The final value of the $C D$ parameter ranges from 0.0 (confident non-cloudy) to 1.0 (confident cloudy). Figure 3 shows an example of the $C D$ parameter applied to the GK2A/AMI data, observed on 28 October 2019 at 07:00 UTC (28 October 2019 at 16:00 KST, Korea local standard time). A strong southwesterly wind blew counterclockwise associated with a mid-latitude cyclone over Manchuria. In the red VIS channel, the reflectance of dust storm had values as high as cloud; however, in the $10.5 \mu m$ channel, the BT of cloud was lower than dust storm (Fig. $3 \mathrm{a}$ and b). Figure $3 \mathrm{c}$ shows that the $C D$ parameter was well correlated with the cloud pixels, and the parameter continuously suppressed regions where the probability of dust storms was low.

\subsection{Dust Tests}

The dust detection algorithm proposed in this study is composed of four dust tests (Fig. 4). In a similar fashion to cloud detection, we derive a set of normalized dust detection index ( $D D I$ ) which range from 0.0 to 1.0 . Using the normalized $D D I$ and the $C D$ parameter, we compute the final $D D$ parameter ranging from 0.0 (confident non-dust) to 1.0 (confident dust).

A widely-used BTD test for dust storms is the BTD between the dirty window channel near $12.3 \mu \mathrm{m}$ and the clean window channel near $10.5 \mu m$ (Iino et al. 2004; Darmenov and Sokolik 2005). Water vapor absorbs more radiation in the 12.3 $\mu m$ channel than the $10.5 \mu m$ channel; on the contrary, the emissivity of dust in the $10.5 \mu \mathrm{m}$ channel is lower than that of the $12.3 \mu \mathrm{m}$ channel (Shenk and Curran 1974; Takashima and Masuda 1987; Wald et al. 1998). Based on the spectral characteristics, we defined DDI1, the 1st dust deletion test, as follows:

$D D I 1=\frac{\left(B T_{12.3}-B T_{10.5}\right)-M I N_{D D I 1}}{M A X_{D D I 1}-M I N_{D D I 1}}$
In general, due to spectral characteristics, the BTD between the $12.3 \mu \mathrm{m}$ and $10.5 \mu \mathrm{m}$ channels is positive in the dust storm, and zero or negative in the cloud and clear-sky (Ackerman et al. 1998). However, the BTD can be positive for various aerosol and cloud conditions (Prata 1989; Iino et al. 2004; Watson et al. 2004). Moreover, the mixture of water vapor and dust can have negative BTDs depending on the composition ratio (Miller et al. 2019). Therefore, in this study, to detect both a strong signal of a dust storm and a weak signal of a mixture, we used -1.0 and 1.5 as the values of $M I N_{D D I 1}$ and $M A X_{D D I 1}$, respectively.

The BTD between the $12.3 \mu \mathrm{m}$ and $10.5 \mu \mathrm{m}$ channels in the dust source region (i.e., deserts) is often similar to a dust storm. To reduce these false alarms, previous studies used the BTD between the $8.7 \mu m$ channel and the $10.5 \mu m$ channel (Darmenov and Sokolik 2005; Liu et al. 2013). At the $10.5 \mu \mathrm{m}$ channel, the emissivity of dust increased with particle size of dust, whereas at the $8.7 \mu \mathrm{m}$ channel, the emissivity of dust was low, due to the reststrahlen band (Salisbury and Eastes 1985; Takashima and Masuda 1987; Salisbury and Wald 1992; Wald et al. 1998). Based on the spectral characteristics, we defined DDI2, the 2nd dust test, as follows:

$D D I 2=\frac{\left(B T_{8.7}-B T_{10.5}\right)-M I N_{D D I 2}}{M A X_{D D I 2}-M I N_{D D I 2}}$

where $M I N_{D D I 2}$ and $M A X_{D D I 2}$ are -3.0 and -0.5 , respectively. In general, the dust on the desert surface is composed of large particles, while the lofted dust storms are composed of small particles. Thus, the BTD between the $8.7 \mu \mathrm{m}$ and 10.5 $\mu m$ channels is higher in dust storms than in their source regions such as arid and semiarid regions (Wald and Salisbury 1995; Wenrich and Christensen 1996; De Paepe and Dewitte 2009).

As the dust intensity weakens, BTs of IR channels show different increasing patterns depending on the channels. In general, dust shows lower BT near $11.2 \mu \mathrm{m}$ than $12.3 \mu \mathrm{m}$, 
(a)

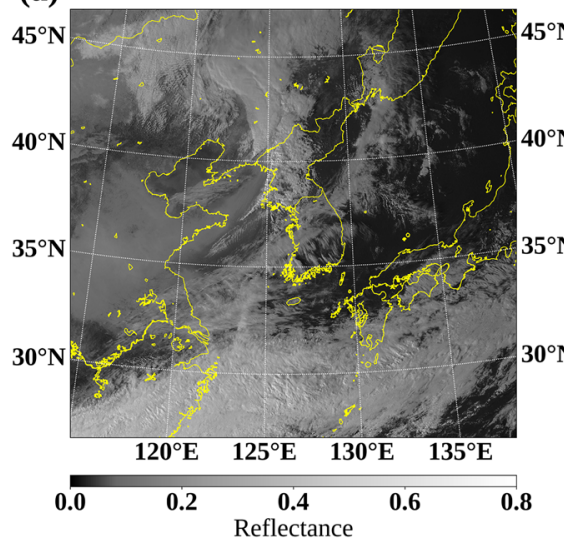

(b)

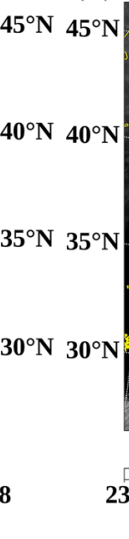

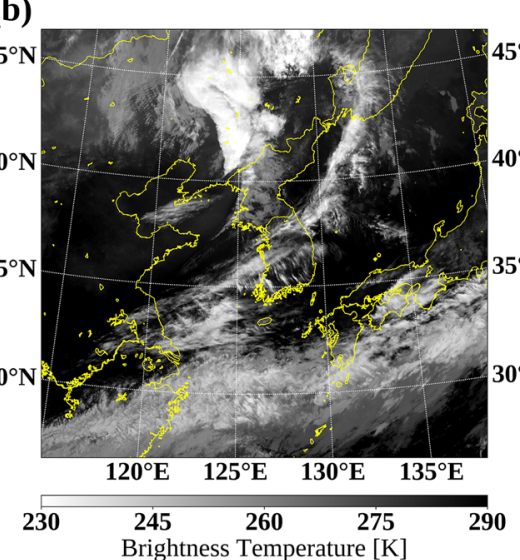

(c)

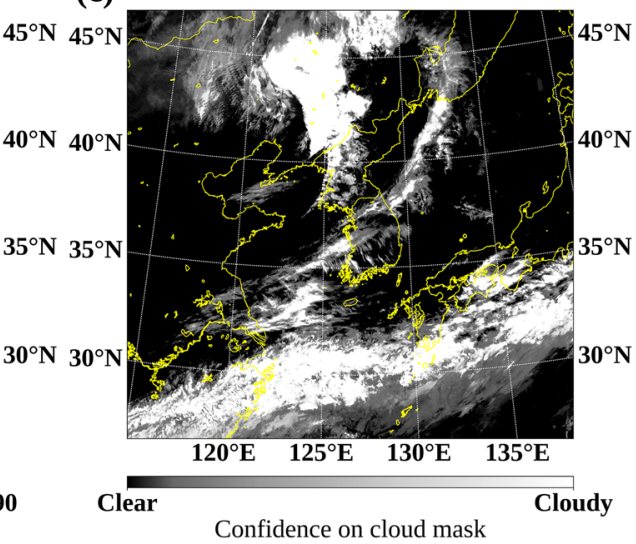

Fig. 3 a Reflectance of the visible channel $(0.6 \mu \mathrm{m})$, b brightness temperature of the thermal infrared channel $(10.5 \mu \mathrm{m})$, and $\mathbf{c}$ derived cloud detection (CD parameter) from GK2A/AMI at 07:00 UTC on 28 October 2019 (28 October 2019 16:00 KST)

and higher BT near $11.2 \mu m$ than $10.5 \mu m$, due to the extinction by absorption and scattering (Sokolik 2002). However, for a weak dust storm with low $\mathrm{AOT}(<0.2)$, the BT of the 11 $\mu m$ channel is higher than $12 \mu m$ channel, and the detection performance of BTD between the $10 \mu \mathrm{m}$ channel and $12 \mu \mathrm{m}$ channel was degraded compared to the detection of strong dust storms ( $\mathrm{Xu}$ et al. 2014). When the dust storm reached the Korean Peninsula, because it is transported over a long distance from source regions and passes through the Yellow Sea, its intensity decreases and water vapor is mixed. Therefore, to detect a weak Asian dust mixed with water vapor, we defined DDI3, the 3rd dust test, as follows:

$D D I 3=\frac{\left(B T_{11.2}-B T_{10.5}\right)-M I N_{D D I 3}}{M A X_{D D I 3}-M I N_{D D I 3}}$

where $M I N_{D D I 3}$ and $M A X_{D D I 3}$ are -1.0 and 1.0, respectively. The BTD between the $11.2 \mu \mathrm{m}$ and $10.5 \mu \mathrm{m}$ channels is generally positive for dust pixels but can be negative depending on water vapor content and dust storm intensity (Xu et al. 2014).

Since the spectral responses in IR channels (especially the $12.3 \mu \mathrm{m}$ channel) are also sensitive to water vapor, false detection or non-detection frequently occur over ocean and surrounding humid regions when using previous BTD tests (Legrand et al. 2001; Chaboureau et al. 2007). Therefore, to monitor dust events passing over the Yellow Sea, we defined DDI4, the 4th dust test, as follows:

$D D I 4=\frac{N_{r}-M I N_{D D I 4}}{M A X_{D D I 4}-M I N_{D D I 4}}$

where $N_{r}$ represents the polarized optical depth index (PODI, or adjusted refractive index), and $M I N_{D D I 4}$ and $M A X_{D D I 4}$ are 1.1 and 1.8, respectively. The PODI is the refractive index of the medium and is used to detect dust storms (Hong 2009). Based on the Fresnel equation and the definition of unpolarized reflectivity (Liou 2002; Sohn and Lee 2013; Lee and Sohn 2015), the PODI is calculated as follows:
$R=1-\frac{B(T)}{B\left(T_{S}\right)}$

$R=\frac{R_{h}+R_{v}}{2}$

$R_{v}=R_{h}{ }^{2}\left(\frac{1+R_{h}{ }^{-1 / 2} \cos 2 \theta}{1+R_{h}{ }^{1 / 2} \cos 2 \theta}\right)^{2}$

$N_{r}=\sqrt{1+\frac{4 R_{h}{ }^{1 / 2} \cos ^{2} \theta}{\left(R_{h}{ }^{1 / 2}-1\right)^{2}}}$

where $R$ is the reflectivity; $R_{h}$ and $R_{v}$ indicate the horizontal and vertical components of reflectivity, respectively; $\theta$ is satellite zenith angle; and $B(T)$ and $B\left(T_{S}\right)$ represent the observed radiance and background radiance, respectively. We used the maximum radiance of the $10.5 \mu m$ channel during 14 days for $B\left(T_{S}\right)$.

To combine the $D D I \mathrm{~s}$, we defined two different combined equations for land and sea separately, as follows:

$D D I_{\text {Land }}=(\max (D D I 1, D D I 3)+2 D D I 3) D D I 2(1-C D)$

$D D I_{\text {Sea }}=(D D I 2+2 D D I 4) D D I 3(1-C D)$

where $\max (A, B)$ represents the MAX between $\mathrm{A}$ and $\mathrm{B}$. $D D I_{\text {Land }}$ and $D D I_{\text {Sea }}$ are the normalized $D D I$ over land and sea, respectively. When normalizing $D D I_{\text {Land }}$, due to changes in the BTDs with diurnal variations of surface temperature, we set different bounds for daytime (1.2 and 2.6) and nighttime (1.6 and 3.0). When normalizing $D D I_{\text {Sea }}$, due to the high specific heat of water, regardless of the time of day, we used MIN and MAX as 0.7 and 2.1, respectively.

For the terminator, normalized $D D I \mathrm{~s}$ can be derived by the blending method. To blend the $D D I \mathrm{~s}$ across the terminator, we used a weighting function with the cosine of the solar zenith angle as follows (Miller et al. 2017): 
Fig. 4 Flow diagram of dust detection for the GK2A/AMI combined dust detection algorithm

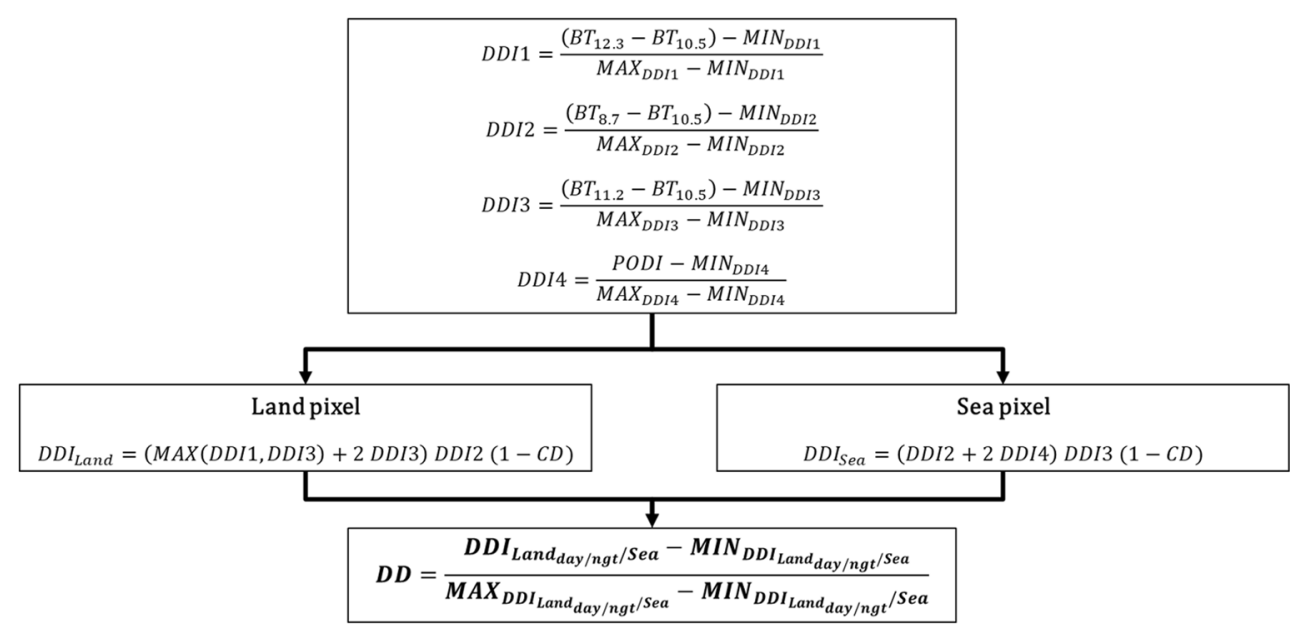

$B_{\text {land }}=\left[\frac{\cos \theta_{\text {Sun }}-M I N_{B}}{M A X_{B}-M I N_{B}}\right]^{1.5}$

where $M I N_{B}$ and $M A X_{B}$ are $\cos 105^{\circ}$ and $\cos 75^{\circ}$, respectively. $\theta_{\text {Sun }}$ indicates the solar zenith angle. Since the sunset and sunrise do not immediately affect the surface temperature, to effectively reflect time lag of the change in the surface temperature by sunset and sunrise, we defined the terminator regions from $75^{\circ}$ to $105^{\circ}$.

Finally, the weighting function was applied to the $D D I \mathrm{~s}$ as follows:

$D D_{\text {land }}=\left(B_{\text {land }} D D I_{\text {Land/daytime }}+\left(1-B_{\text {land }}\right) D D I_{\text {Land/nightime }}\right)$

where $D D I_{\text {Land/daytime }}$ and $D D I_{\text {Land/nightime }}$ indicate the normalized $D D I_{\text {Land }}$ in daytime and nighttime, respectively. The blending method across the terminator regions is able to reflect the natural transition of the sun and eliminate the discontinuity of the dust detection signal (Miller et al. 2017). The values of the $D D$ parameter defined in this study range from 0.0 (confident non-dust) to 1.0 (confident dust).

Figure 5 shows an example of the $D D$ parameter applied to GK2A/AMI data, observed on 28 October 2019 at 07:00 UTC (28 October 2019 at 16:00 KST). Strong southwesterly dust storms were transported from Hebei and Qingdao and passed over the northern Yellow Sea. The dust storm pixels are not displayed in the BT near $10.5 \mu m$; however, they are observed clearly in the DDI product (Fig. 5a-e). In the DDI2 product, the values for the dust source regions are low, discriminated from the dust storm itself, but the values for clouds are as high as the dust storm (Fig. 5c). The DDI1 and DDI3 products showed high values for the dust storm, discriminated from clouds; however, in comparison with the DDI1 product, the DDI3 product clearly detected weak dust pixels (Fig. 5b and d). The DDI4 product was useful for distinguishing the weak dust pixels from the non-dust pixels in the sea areas (Fig. 5e). Figure $5 \mathrm{f}$ shows that the final $D D$ parameter, was highly correlated with dust pixels and suppressed regions where the probability of the dust storm was low.

\subsection{Construction of False Color Imagery}

We used false color imagery to display the $D D$ parameter and adopted the DEBRA developed by Miller et al. (2017). First, we defined the baseline imagery (BI). To prevent discontinuity from using different BI depending on the observation time, we employed the $10.5 \mu \mathrm{m}$ channel for the BI regardless of the time of day as follows:

$B I=1-\frac{B T_{10.5}-M I N_{B I}}{M A X_{B I}-M I N_{B I}}$

where $M I N_{B I}$ and $M A X_{B I}$ indicate the MIN and MAX of BT near $10.5 \mu \mathrm{m}$ in the domain, respectively. The BT near 10.5 $\mu m$ can change depending on the surface temperature and atmospheric conditions and we used the $90 \%$ upper limit and $10 \%$ lower limit as the MAX and MIN.

For dust-enhanced false color imagery, we modulated the $\mathrm{BI}$ with the $D D$ parameter and a weighting factor in each color gun (R, G, and B component) to emphasize the pixels with higher $D D$ parameters (Miller et al. 2017, 2020). In this study, each color component is represented as follows:

Red component $=B I(1-\min (D D, 0.5))+D D$

Green component $=B I(1-\min (D D, 0.5))+0.1 D D$

Blue component $=B I(1-\min (D D, 0.5))+D D$

where $\min (A, B)$ represents the MIN between $\mathrm{A}$ and $\mathrm{B}$, and the MIN and MAX of each color gun are 0.0 and 1.2, respectively. The color of dust storm pixels changes depending on the combination of the weighting factor applied to the DD parameter of each color gun (Miller et al. 2017). We applied the 
(a)

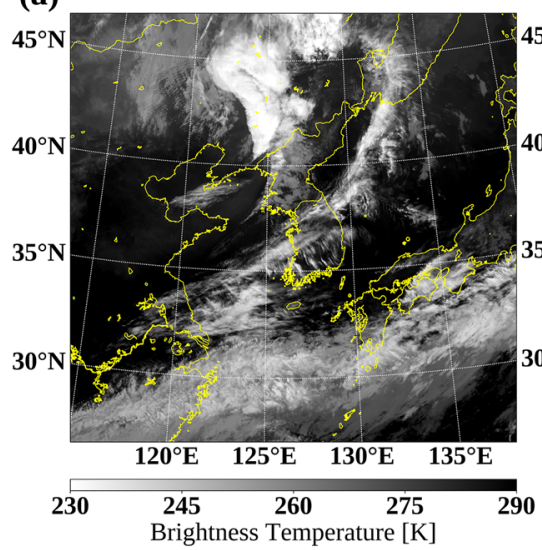

(d)

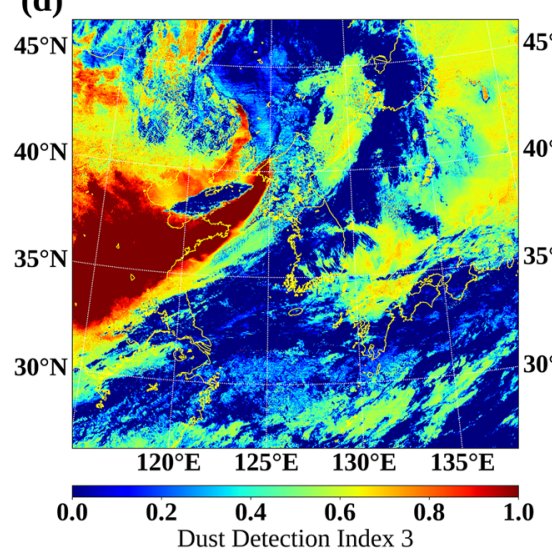

(b)

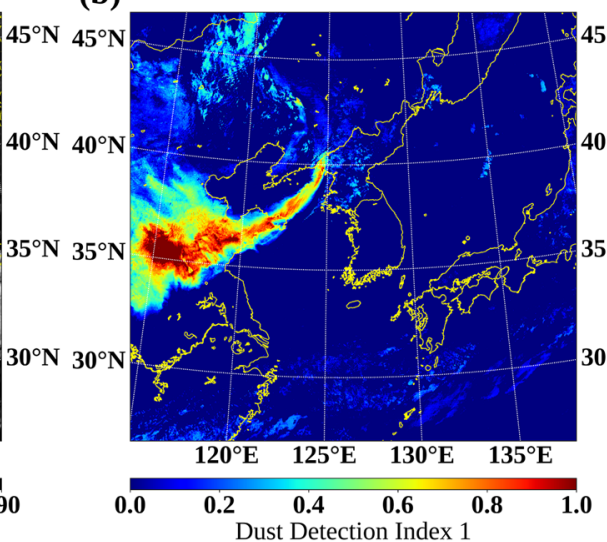

(e)

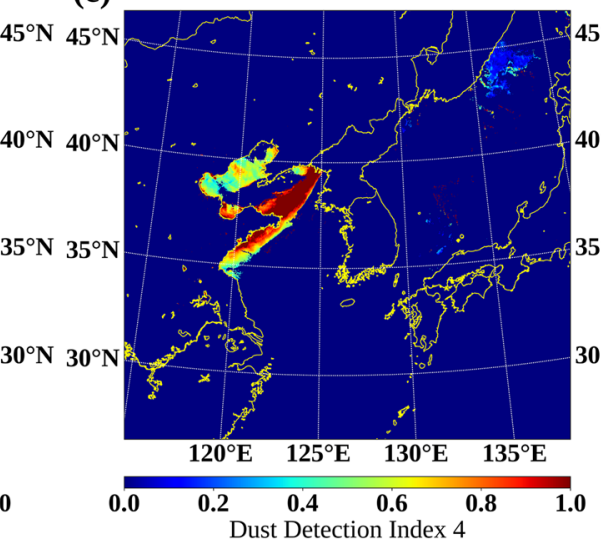

(c)

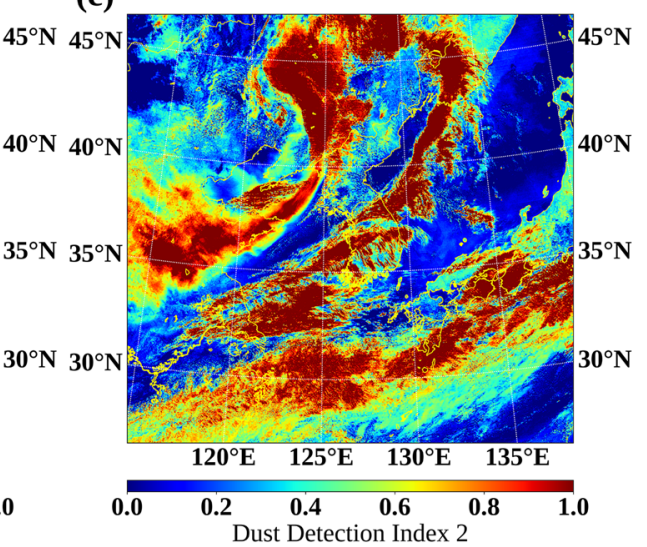

(f)

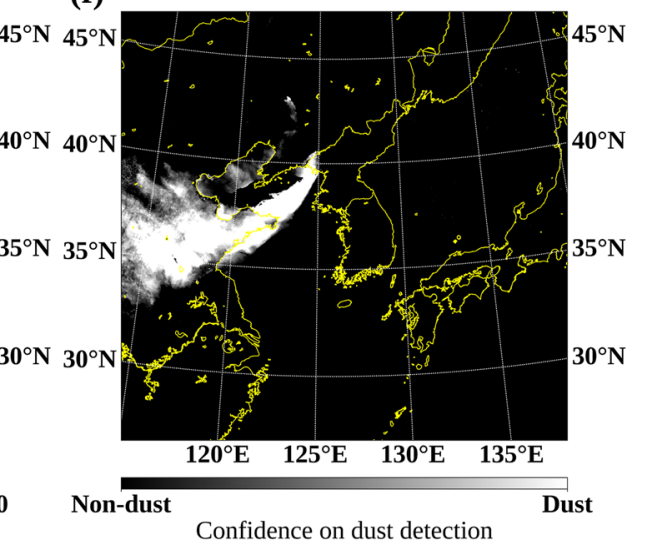

Fig. 5 a Brightness temperature of the thermal infrared channel $(10.5 \mu m$ ), $\mathbf{b}$ dust detection index (DDI) 1, $\mathbf{c ~ D D I 2 , ~} \mathbf{d}$ DDI3, $\mathbf{e}$ DDI4, and $\mathbf{f}$ derived dust detection (DD) parameter from GK2A/AMI observed at 07:00 UTC on 28 October 2019 (28 October 2019 16:00 KST)

weighting factor of 0.1 in G component (Eq. 25) to display the dust storm as magenta. The false color imagery to display DD parameter combined with BI diminishes false detection of algorithm. For example, low thin clouds and fogs are frequently false-detected as dust storms with a low DD parameter due to their IR spectral properties similar to dust storm. Because low thin clouds and fogs have low BT near $10.5 \mu \mathrm{m}$, their pixels shows a high BI. As a result, values of each color gun of the pixels with a high BI and low DD close to MAX, and the false-detected pixels are displayed as gray similar to clouds and undetected pixels. Thus, false detections with low DD parameter are reduced in false color imagery, and the method is advantageous for operational dust monitoring in real time.

\section{Results}

A dust event that occurred during 27-29 October 2019 was selected to validate the combined dust detection algorithm. The dust originated in the desert areas of northern China and Mongolia, was carried aloft to the southeastern regions in China, and ultimately reached the Korean Peninsula. As shown in Fig. 6, surface weather charts, $925 \mathrm{hPa}$ stream line, and column integrated particulate matter 10 micrometers or less in diameter $\left(P M_{10}\right)$ derived from the Asian Dust Aerosol Model (ADAM) were used to explain the onset, transport, and dissipation of Asian dust. The ADAM was originally developed by integrating the Asian dust emissions algorithm, a chemical transport model, and Community Multiscale Air Quality (CMAQ) model (In and Park 2003; Park and In 2003; Byun and Schere 2006). Then, KMA has improved the ADAM by combining anthropogenic emissions with a daily dust emissions reduction factor and assimilating in-situ PM and satellite-derived AOT (Hong et al. 2019; Lee et al. 2019).

A migratory cyclone was located in northern Mongolia on 27 October 2019 at 00:00 UTC (27 October 2019 at 09:00 KST), which raised dust by upward airflow (Fig. 6a-c). As the cyclone intensified, more fine dust was lofted into the atmosphere and $P M_{10}$ was increased. As the cyclone moved to eastern Mongolia on 27 October 2019 at 18:00 UTC (28 October 2019 at 03:00 KST), dust spread out to Hebei and Manchuria (Fig. 6d-f). As the cyclone moved over Manchuria, the dust rotated counterclockwise around the cyclone, and moved over Qingdao, Nanjing, the Bohai Sea, the Yellow Sea, and the northern Korean Peninsula by the anticyclone 
on 28 October 2019 by 12:00 UTC (28 October 2019 at 21:00 KST) (Fig. 6g-i). As the cyclone moved to eastern Manchuria, the anticyclones were intensified in eastern China. On 29 October 2019 at 06:00 UTC (29 October 2019 at 15:00 KST), the dust storms were transported over Shanghai, Hangzhou, the southern Yellow Sea, the southern Korean Peninsula, and the East Sea by northwesterly winds blown from the anticyclone (Fig. 6j-1).

\subsection{Comparison with Ground-based Lidar}

For selected dust cases, we used AD-Net data to calculate the aerosol extinction coefficient, spherical extinction coefficient, and depolarization ratio to compare with the results from the combined dust detection algorithm from GK2A/AMI. The aerosol extinction coefficient is a parameter that measures the extinction coefficient of non-spherical aerosols such as dust. The spherical extinction coefficient is a parameter observing the extinction coefficient of spherical aerosols including air pollutants, sea salt, and sulfate. The depolarization ratio represents the ratio of non-spherical aerosols in all aerosols (Sugimoto et al. 2003, 2013). In general, for pure dust, the attenuated backscatter coefficient, dust extinction coefficient, and depolarization ratio have high values, whereas the spherical extinction coefficient has a low value (He and Yi 2015; Zhou et al. 2018).

On 28 October 2019 at 18:00 UTC (29 October 2019 at 03:00 KST), the dust storm moved from Shanghai over the Yellow Sea, and eventually reached Seoul, Korea. At that time, the Gwanak Seoul station observed a high dust extinction coefficient of $0.36 / \mathrm{km}$, high volume depolarization ratio of 0.31 , and low sphere extinction coefficient of $0.03 / \mathrm{km}$ (Fig. 7a). In the combined dust detection algorithm from the GK2A/AMI, the weakened dust storm was widely distributed around the Gwanak Seoul station (Fig. 7b). On 29 October 2019 by $06: 30$ UTC (29 October 2019 at 15:30 KST), the dust storm had moved from Nanjing, Hangzhou, and Shanghai, to pass over the southern regions of the Yellow Sea, and reach Jeju Island. At that time, the Gosan Jeju station observed a high dust extinction coefficient of $0.32 / \mathrm{km}$, high volume depolarization ratio of 0.19 , and high sphere extinction coefficient of $0.31 / \mathrm{km}$ (Fig. 7c). In the combined dust detection algorithm from the GK2A/AMI, the weakened dust storm was widely distributed around the Gosan Jeju station (Fig. 7d).

The dust storms, which were observed at the Gwanak Seoul station (Fig. 7a and b) and the Gosan Jesu station (Fig. 7c and d), had a similar source region and transportation route; however, they showed different properties (Fig. 7b and d). The dust storm observations at the Gwanak Seoul station showed a low sphere extinction coefficient, whereas observations at the Gosan Jeju station showed a high sphere extinction coefficient (Fig. 7a and c). Based on previous studies, the dust storm observed at the Gwanak Seoul station showed the typical characteristics of a pure dust storm (He and Yi 2015; Zhou et al. 2018). In comparison, before the dust storm reached Jeju Island, the Gosan Jeju station measured a high spherical extinction coefficient of $0.58 / \mathrm{km}$. When the dust storm reached Jeju Island, the dust extinction coefficient increased and showed a high value of $0.26 / \mathrm{km}$ (Fig. 7c). Although the spherical extinction coefficient decreased, it still showed a high value of $0.28 / \mathrm{km}$ compared with the observed at Gwanak Seoul station (Fig. 7a and c). This means that the spherical aerosols (mostly air pollutants) reached Jeju Island before the dust storm, and the dust observed at the Gosan Jeju station on 29 October 2019 at 06:30 UTC (29 October 2019 at 15:30 KST) was mixed with air pollution aerosols (Sugimoto et al. 2015).

\subsection{Comparisons of Dust Imagery Products During the Day}

For qualitative evaluation at daytime, we used the true RGB imagery and the current dust RGB imagery from Himawari-8/AHI (developed by KMA NMSC). On 27 October 2019 at 05:40 UTC (27 October 2019 at 14:40 KST), a dust storm originating in northern China and Mongolia moved to the southeastern regions by northwesterly winds (Fig. 8a-c). It was difficult to distinguish the lofted dust from the dust source regions in the true RGB imagery. The dust RGB imagery was able to capture the dust storm, but similar colors over the source region and surrounding land areas confused dust monitoring (Fig. 8a and b). The lofted dust was more clearly detected by using the combined dust detection algorithm applied to GK2A/AMI. The regions with high $D D$ values match the magenta regions in the dust RGB imagery well (Fig. 8c).

On 29 October 2019 at 02:10 UTC (29 October 2019 at 11:10 KST), a weak dust storm tracked from Nanjing, Hangzhou, and Shanghai to the southern Yellow Sea and Korean Peninsula and was widely distributed. It was further transported to the southeastern regions by northwesterly winds and extended northeast (Fig. 8d-f). In the true RGB imagery, it was difficult to detect the dust over land owing to similar signals from the land surface in eastern China, but the overall distribution of the dust over the sea was detected due to the low reflectance of the sea (Fig. 8d). In the Yangtze River Estuary and Bohai Sea, as water with high suspended particulate matter (SPM) showed similar reflectance to the dust, it was difficult to accurately detect the dust storm over the sea in the true RGB imagery. In the dust RGB imagery, the lofted dust over land and sea was effectively detected. However, as the dust weakened, their colors became similar to the surrounding regions (Fig. 8e). Although the dust weakened and the value of the $D D$ parameter decreased, the dust pixels in the new dust- 

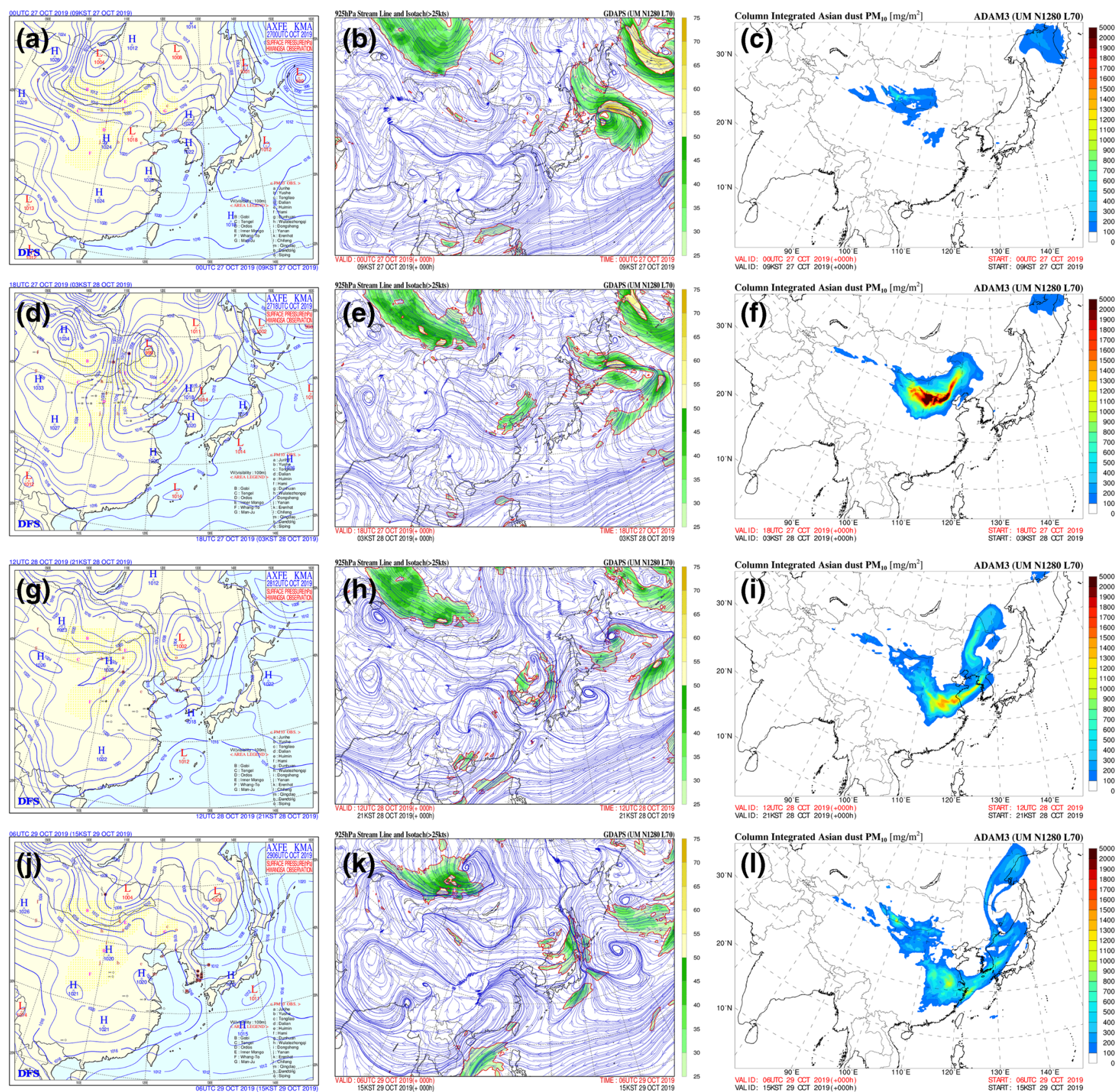

Fig. 6 Surface weather charts for the Asian dust storm, where the red weather symbols represent the dust storm by in-situ measurement and the yellow coloured areas indicate the forecasted dust storm, $925 \mathrm{hPa}$ stream line for UM GDAPS model, and forecast charts for Asian Dust Aerosol Model 3 (ADAM3) simulated column integrated PM10 produced by
Korean Meteorological Administration (KMA) on (a-c) 27 October 2019 at 00:00 UTC (27 October 2019 at 09:00 KST), (d-f) 27 October 2019 at 18:00 UTC (28 October 2019 at 03:00 KST), (g-i) 28 October 2019 at 12:00 UTC (28 October 2019 at 21:00 KST), and (j-I) 29 October 2019 at 06:00 UTC (29 October 2019 at 15:00 KST) enhanced imagery were clearly separated from the surrounding pixels with a higher confidence than in the dust RGB imagery. It was difficult to monitor the dust storm in the dust RGB imagery when it moved to the northern East Sea. However, it could be clearly detected using the combined dust detection algorithm (Fig. 8f).

\subsection{Comparisons with Satellite-based Dust Products in Dawn and Dusk}

To account for the diurnal variations in IR channels, we applied different thresholds for daytime and nighttime in land, and defined the terminator region for the blending technique. 
(a)

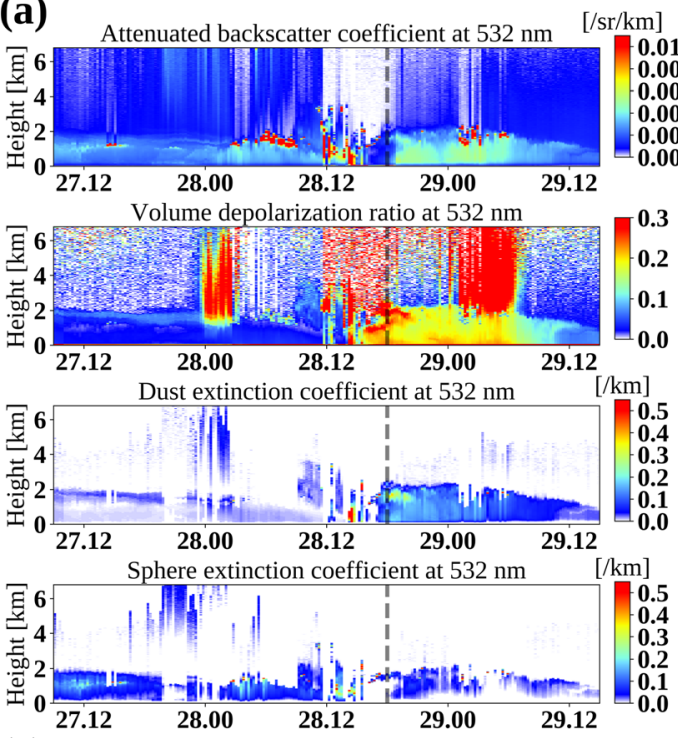

(c)
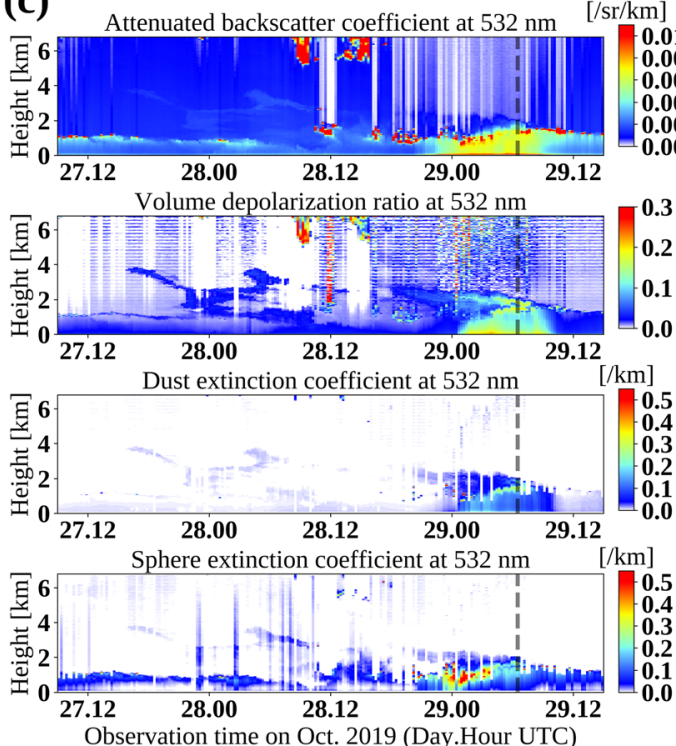

Fig. 7 Measurements (attenuated backscatter coefficient, volume depolarization ratio, dust extinction coefficient, and sphere extinction coefficient) observed at (a) Seoul station and (c) Jeju station, where the dashed black lines represent the observation time of GK2A/AMI, and the (b)

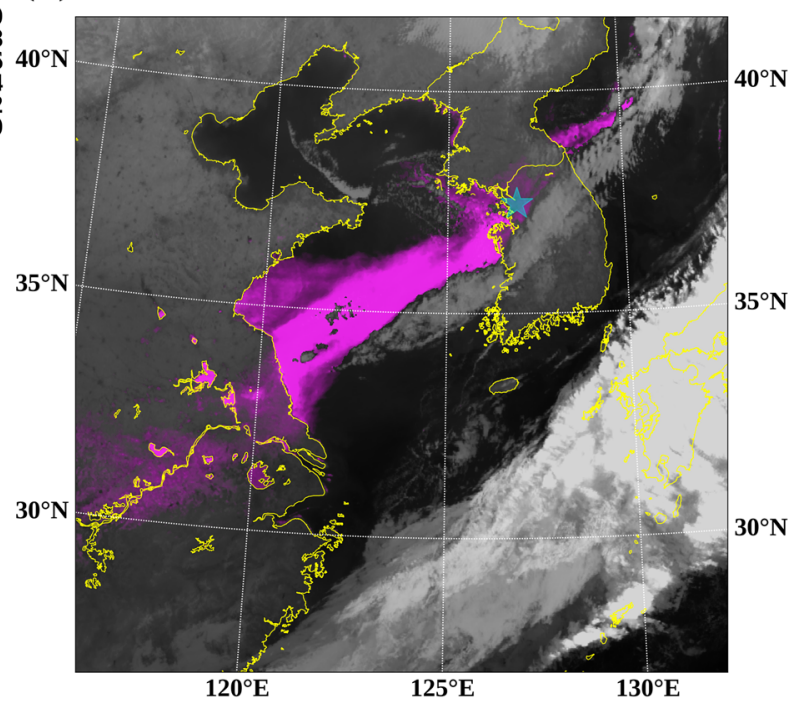

(d)

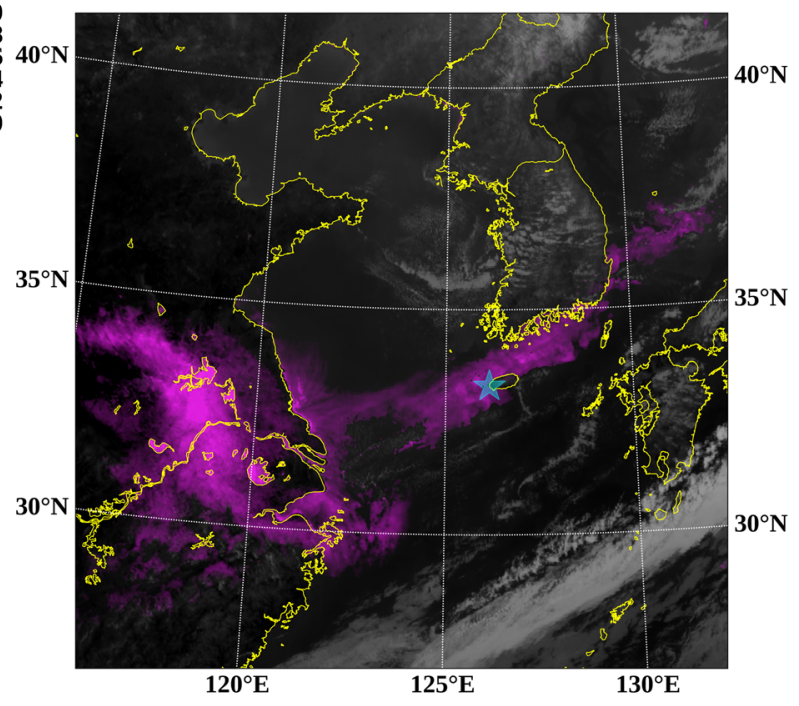

derived dust detection from GK2A/AMI observed on (b) 28 October 2019 at 18:00 UTC (29 October 2019 at 03:00 KST) and (d) 29 October 2019 at 06:30 UTC (29 October 2019 at 15:30 KST), where the blue stars indicate the locations of the AD-Net stations

were consistent with the dust distributions in the dust RGB imagery (Fig. 9c).

On 28 October 2019 at 08:40 UTC (28 October 2019 at 17:40 KST), the dust storm over Hebei was transported to the southeastern regions and reached the northern Yellow Sea. The dust storm was affected by the cyclone located in Manchuria, and the distribution of dust extended towards the northeast (Fig. 9d-f). At dusk, the dust storm over the northern Yellow Sea was not detected in the true RGB imagery (Fig. 9d). In the dust RGB imagery, the dust storm over the northern Yellow Sea was detected clearly. However, it was difficult to accurately detect the dust storm due to the 
(a)

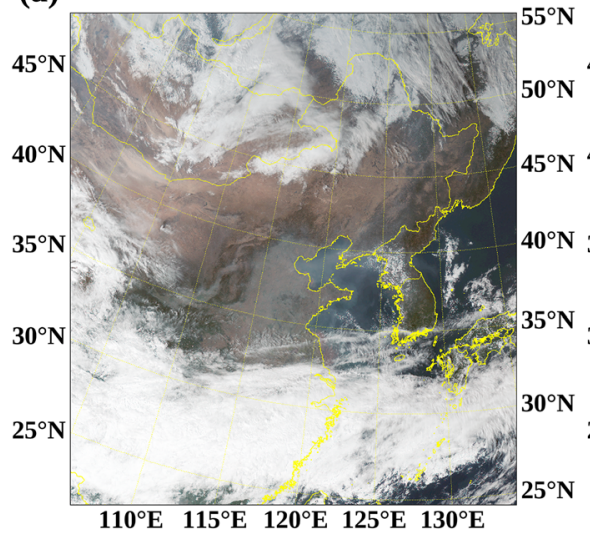

(d)

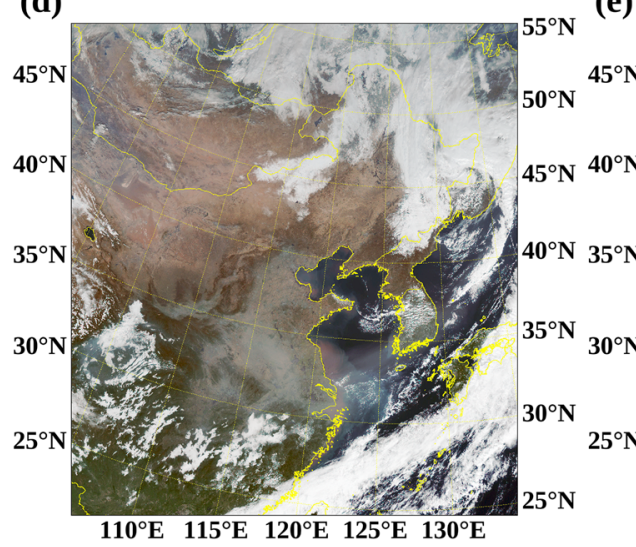

(b)

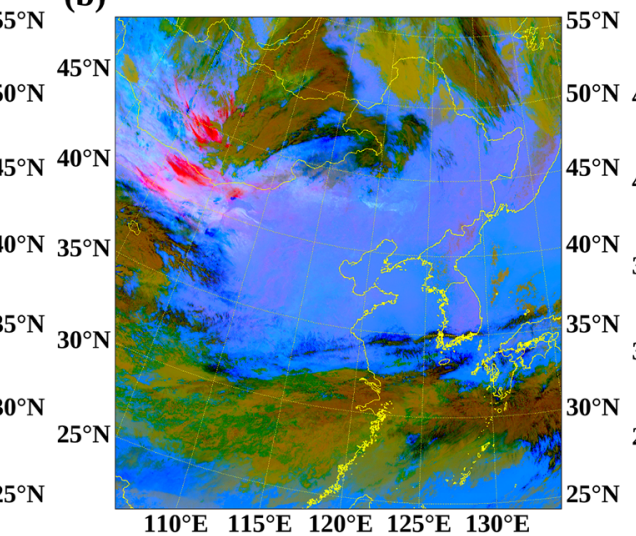

(e)

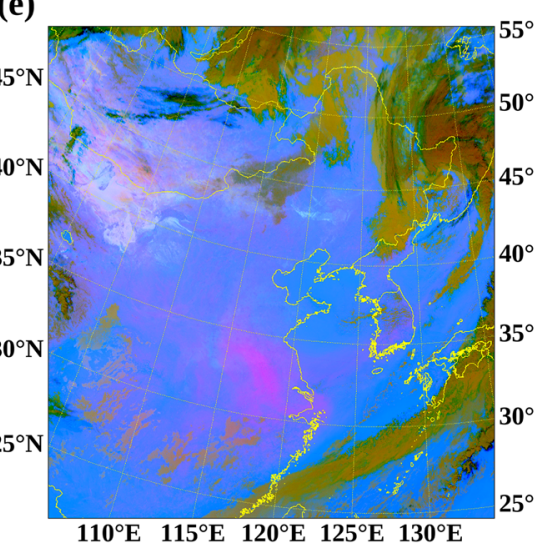

(c)

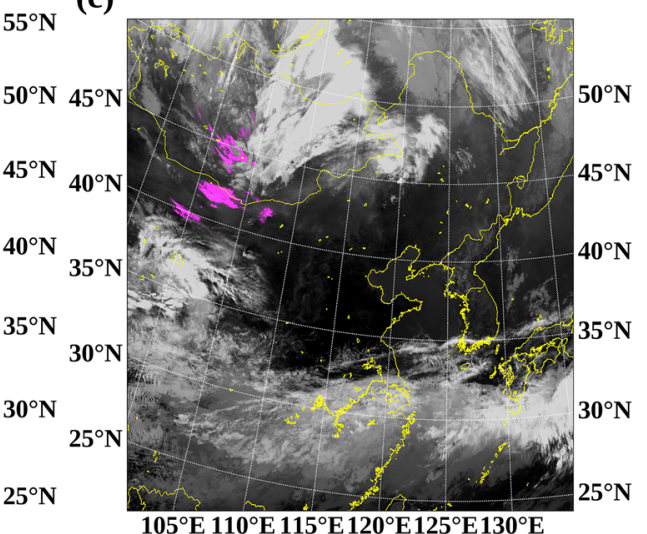

(f)

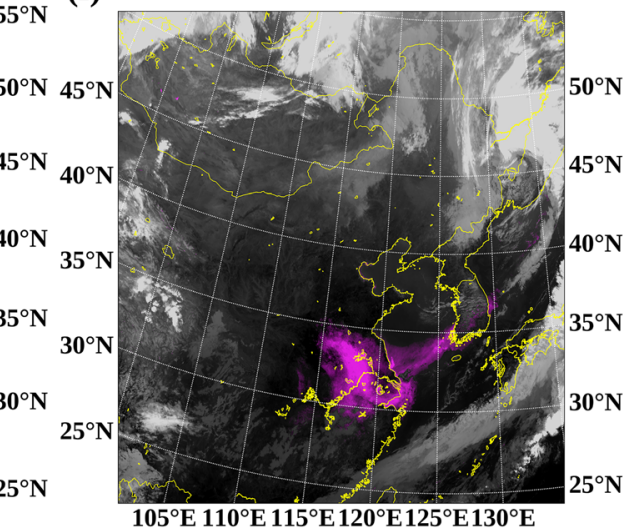

Fig. 8 True RGB images and dust RGB images derived from Himawari-8/AHI, and the derived dust detection from GK2A/AMI observed on (a-c) 27 October 2019 at 05:40 UTC (27 October 2019 at 14:40 KST) and (d-f) 29 October 2019 at 02:10 UTC (29 October 2019 at 11:10 KST)

weakened dust signal over the Bohai Sea (Fig. 9e). In the dustenhanced imagery from the GK2A/AMI, the regions of high $D D$ parameter were consistent with the dust distributions in the dust RGB imagery, and the combined algorithm showed better performance for the detection of dust airborne over the northern Yellow Sea and eastern China, as compared to the dust RGB imagery (Fig. 9f).

On 28 October 2019 at 22:20 UTC (29 October 2019 at 07:20 KST), the weak dust storm that moved from Nanjing and Shanghai to the southern Yellow Sea, southern Korean Peninsula, and the East Sea was widely distributed. The dust distribution extended northeast by the cyclone located in eastern Manchuria; however, the overall dust storm was transported to the southeastern regions (Fig. 9g-i). Since it was observed at dawn, the dust storm was not shown in the true RGB imagery (Fig. 9g). Although the dust storm was detected in the dust RGB imagery, the weak dust storm over land and sea was not clearly shown (Fig. 9h). In the combined dust detection algorithm, the regions of high $D D$ parameter values matched the dust distribution in the dust RGB imagery well, and the combined algorithm showed better performance for the detection of weak dust lofted over both land and sea, as compared to the dust RGB imagery (Fig. 9i).

\subsection{Comparisons with Satellite-based Dust Products in the Nighttime}

For qualitative evaluation at nighttime, we used the $10.5 \mu \mathrm{m}$ channel imagery from GK2A/AMI and the dust RGB imagery from Himawari-8/AHI. On 27 October 2019 at 16:30 UTC (28 October 2019 at 01:30 KST), a dust storm was transported to the southeastern regions by northwesterly winds and was partially affected by the cyclone located at the border of southeastern Mongolia (Fig. 10a-c). The dust RGB imagery clearly detected the dust, and the results of the combined dust detection algorithm from the GK2A/AMI were consistent with those of the dust RGB imagery (Fig. 10b and c). The partial region of dust, detected as a strong dust storm in the dust RGB imagery and the result of the combined dust detection algorithm, is displayed in blurred grey and distinguished from the neighboring clouds in the $10.5 \mu \mathrm{m}$ channel imagery (Fig. 10a). In particular, the dust signal, enclosed by the clouds of the cyclone located over western Manchuria, was shown very weak in the dust RGB imagery, but the dust signal was well visible in the combined dust detection algorithm.

On 28 October 2019 at 13:50 (28 October 2019 at 22:50 KST), the dust storm lofted from Hebei to the Yellow Sea was 

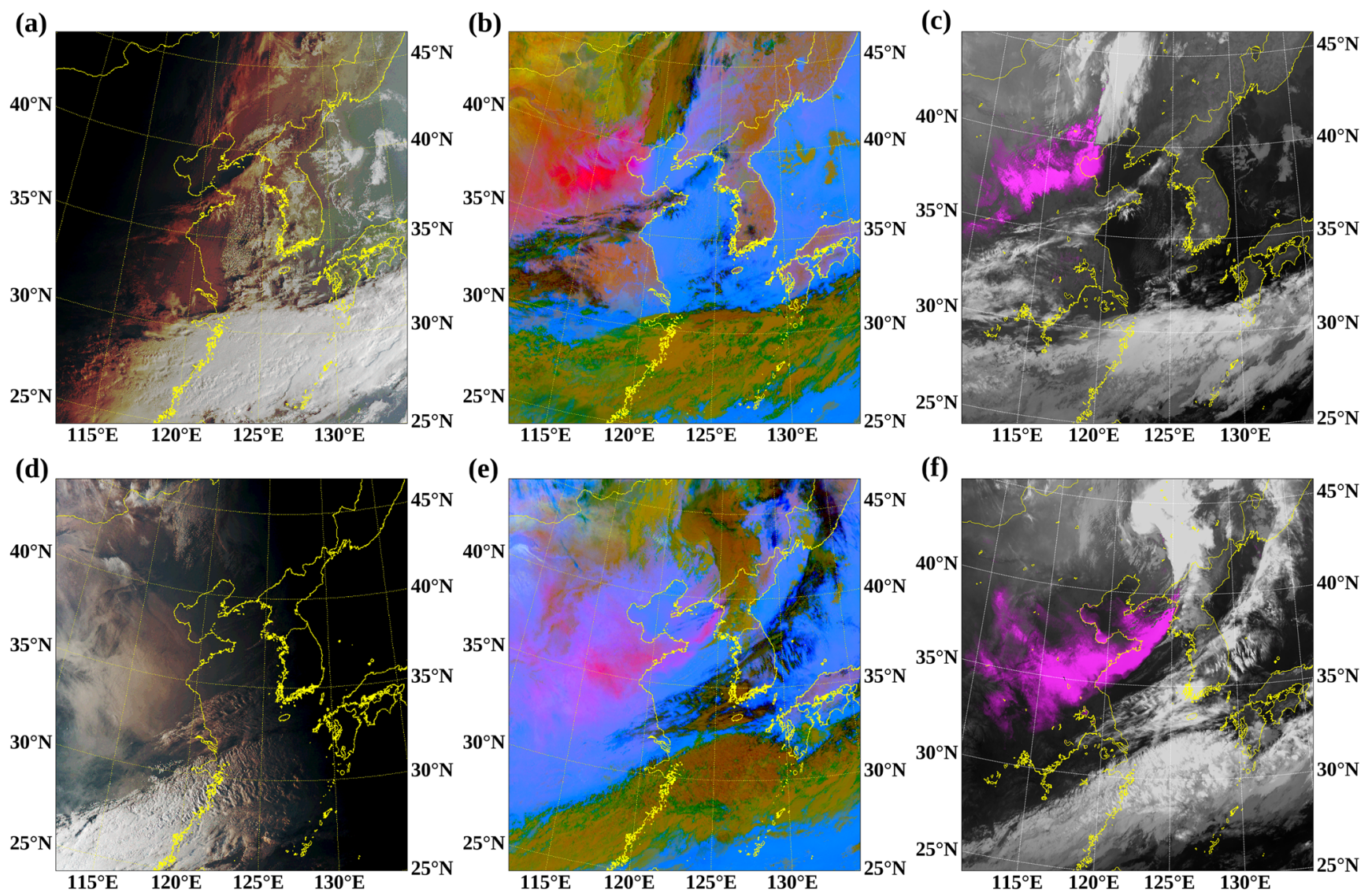

(e)

(f) $45^{\circ} \mathrm{N}$
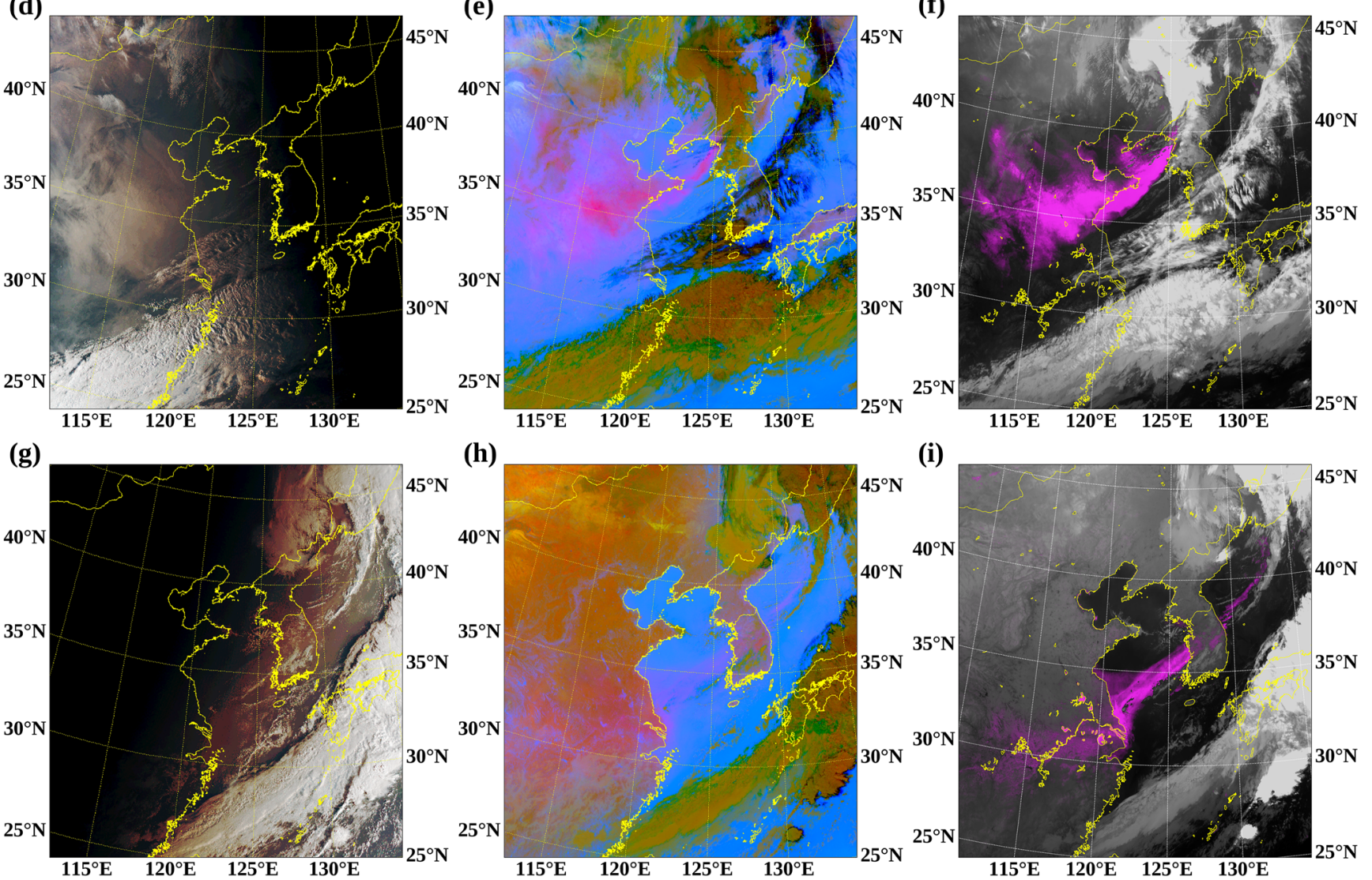

(h)

(i)

$115^{\circ} \mathrm{E} \quad 120^{\circ} \mathrm{E} \quad 1^{\circ} 5^{\circ} \mathrm{E} \quad 130^{\circ} \mathrm{E}$
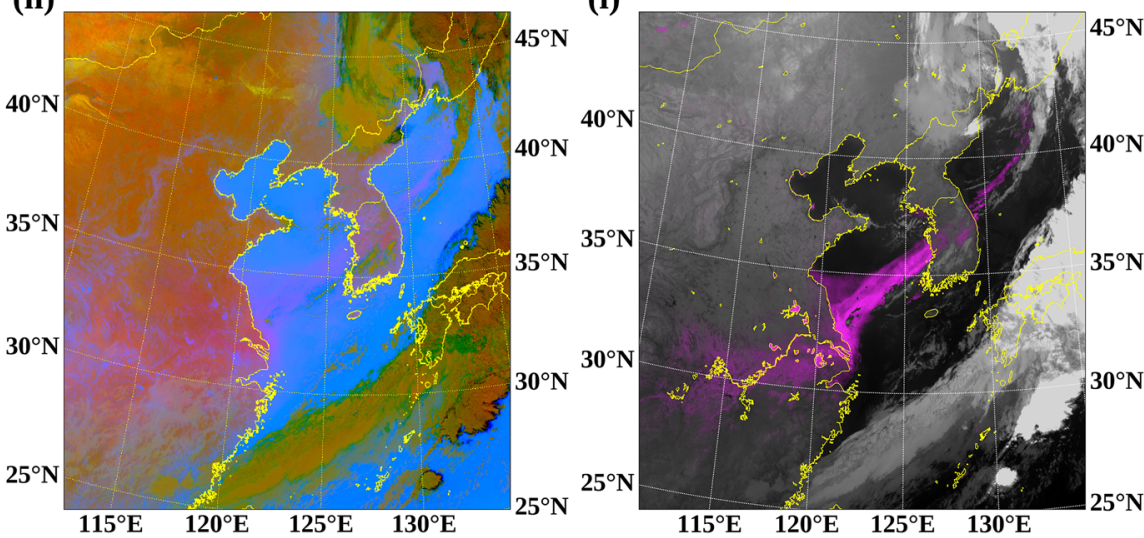

28 October 2019 at 08:40 UTC (28 October 2019 at 17:40 KST), and (g-i) 28 October 2019 at 22:20 UTC (29 October 2019 at 07:20 KST) c) 27 October 2019 at 22:40 UTC (28 October 2019 at 07:40 KST), (d-f)

moved to the Korean Peninsula and transported to the southeastern regions (Fig. 10d-f). In the $10.5 \mu \mathrm{m}$ channel, the decreased BT was detected due to the dust storm over the sea, but the dust storm over the land was not differentiated from the surrounding area (Fig. 10d). In the dust RGB imagery, the overall dust storm was shown, but the weakened dust over the sea was not discriminated from fog. It was also difficult to identify the weakened dust over eastern China due to the reduced dust signal (Fig. 10e). Compared with the dust RGB imagery, the combined dust detection algorithm showed better performance in distinguishing the weakened dust airborne over the sea from fog. However, the weak dust over eastern China was still not well detected (Fig. 10f).

\subsection{Comparisons with Satellite-based Dust Products in Coastal Regions}

When the BTD based on IR channels was used to detect dust storms, false alarms and discontinuity in the coastal boundary area were found frequently. This was due to a difficulty in 
(a)

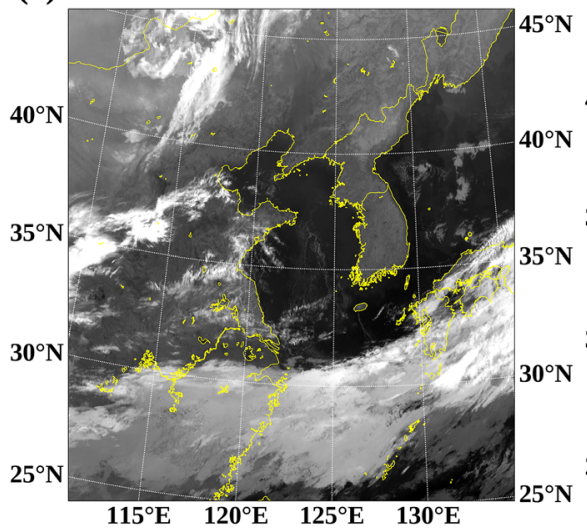

(d)

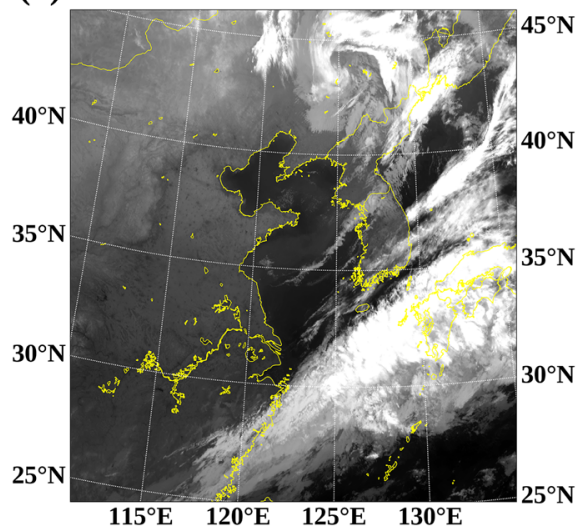

(b)

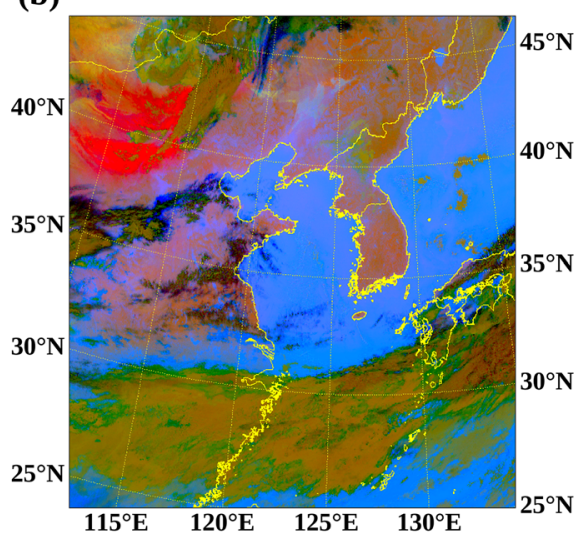

(e)

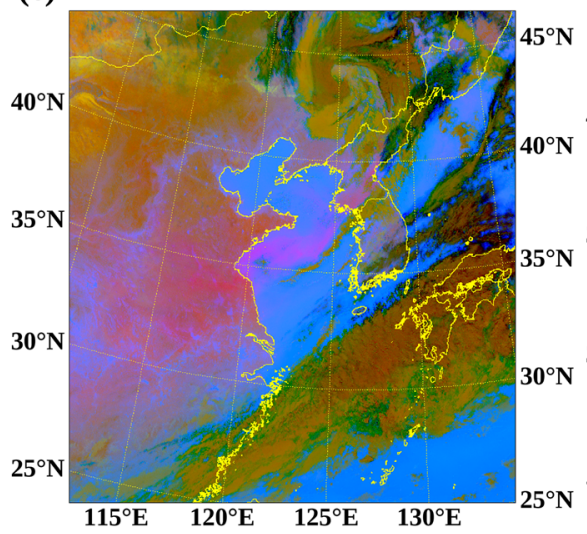

(c)

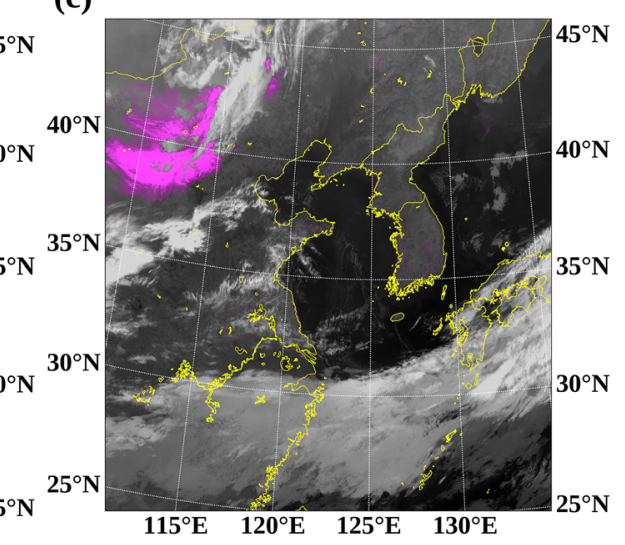

(f)

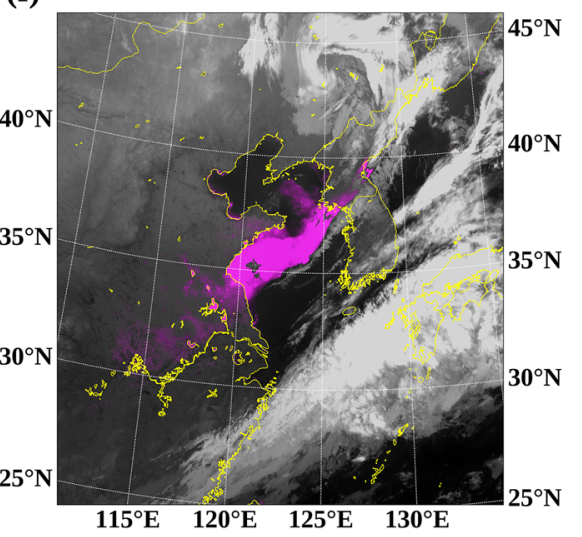

Fig. 10 Brightness temperature of thermal infrared channel $(10.5 \mu \mathrm{m})$ from GK2A/AMI, dust RGB images derived from Himawari-8/AHI, and the derived dust detection from GK2A/AMI observed on (a-c) 27
October 2019 at 16:30 UTC (28 October 2019 at 01:30 KST) and (d-f) 28 October 2019 at 13:50 UTC (28 October 2019 at 22:50 KST) properly reflecting the environmental condition based on the surface type. To resolve the limitations, we proposed a different algorithm for detecting the dust storm lofted over land (Eq. 19) and sea (Eq. 20). Thus, it is necessary to examine the continuity of the dust detection method along the boundary between land and sea. To evaluate this discontinuity, we sorted out the daytime cases, including the widely distributed dust events over land and sea discussed in Section 4.2, but for different times.

On 28 October 2019 at 04:50 UTC (28 October 2019 at 13:50 KST), a strong dust storm over Qingdao and the Bohai Sea was transported southeast, and the partial dust storm was affected by the cyclone located over Manchuria (Fig. 11a-c). On 29 October 2019 at 00:20 UTC (29 October 2019 at 09:20 KST), the weakened dust storm moved from Nanjing, Hangzhou, and Shanghai to the southern regions of the Yellow Sea, Korean Peninsula and East Sea, and was widely distributed over the southeastern regions, extending toward the northeast (Fig. 11d-f). In the true RGB imagery, it was difficult to clearly identify the spatial distribution of dust storms over the Bohai Sea and the Yangtze River Estuary due to the reflectance of high SPM water (Fig. 11a and d).
The overall pattern of the dust storm was shown in the dust RGB imagery (Fig. 11b and e), but it was difficult to detect the weakened dust lofted over eastern China and the Korean Peninsula (Fig. 11e). In the new dust-enhanced imagery from the GK2A/AMI, the dust storm over the land and sea was continuously shown and was well detected over the coastal regions of the Bohai Sea and Yangtze River Estuary (Fig. 11c).

\subsection{Comparisons with LEO Satellite Products}

The FMF and AOT depend on the dust event characteristics, including the intensity and source region of the dust storm and the surface property (Kaufman et al. 2005; Jones and Christopher 2007, 2011; Lee et al. 2017; Sayer et al. 2018b). For the cases of weakened dust storms transferred to the Yellow Sea away from the source region, their intensity could decrease and they would be mixed with sea salt. In the new dust-enhanced imagery from GK2A/AMI, the regions of high $D D$ parameter values were consistent with high AOT and low FMF derived from S-NPP/VIIRS (Fig. 12). On account of varying FMF and AOT in dust events, to quantitatively verify the 
(a)

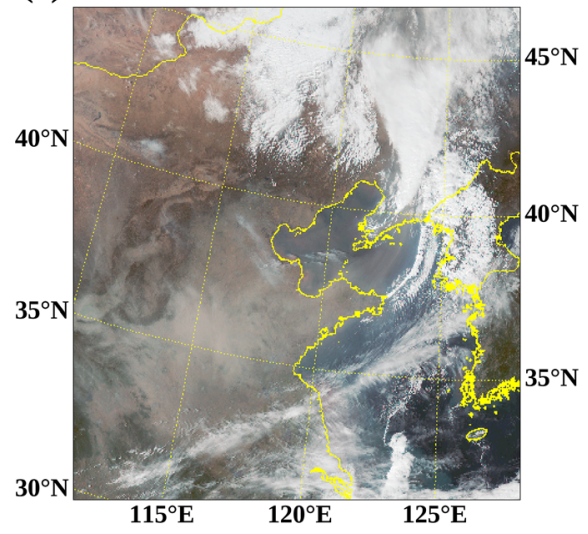

(d)

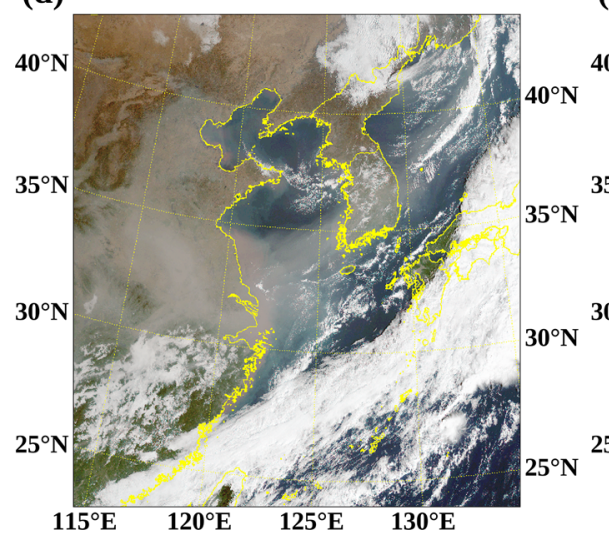

(b)

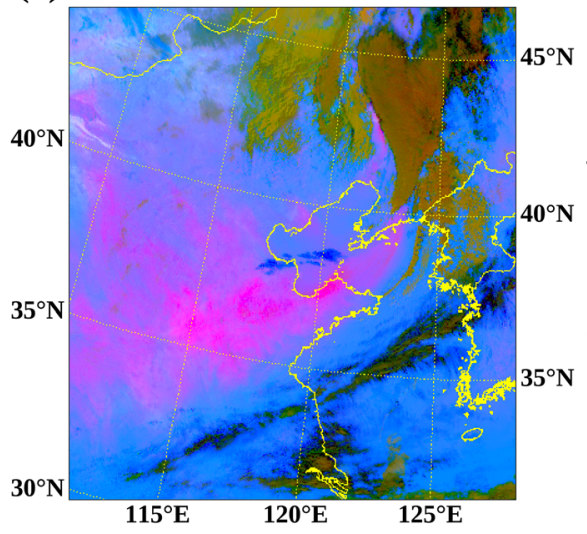

(e)

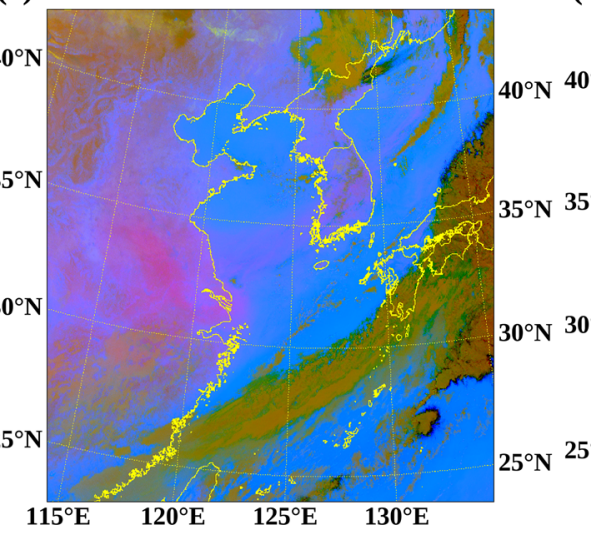

(c)

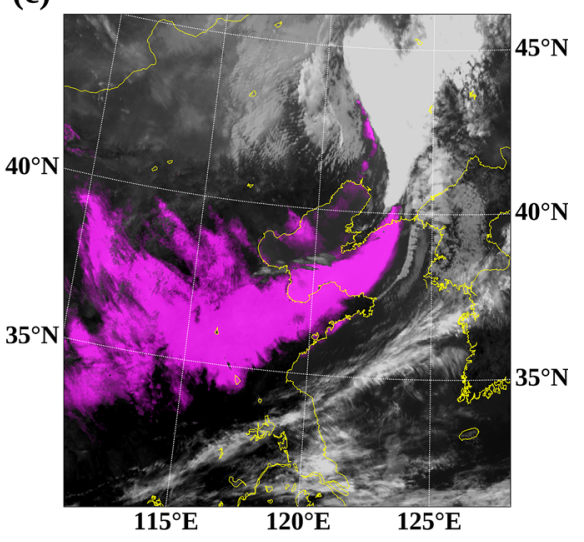

(f)

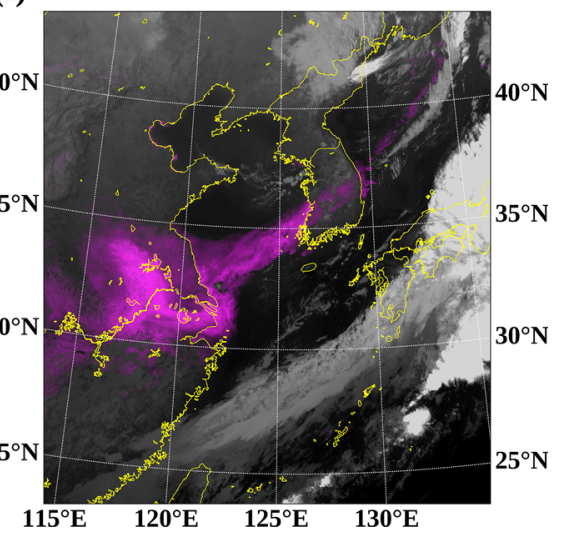

Fig. 11 True RGB images and dust RGB images derived from Himawari-8/AHI, and the derived dust detection from GK2A/AMI observed on (a-c) 28 October 2019 at 04:50 UTC (28 October 2019 at 13:50 KST) and (d-f) 29 October 2019 at 00:20 UTC (29 October 2019 at 09:20 KST)

GK2A/AMI dust detection in different dust storm conditions, Park et al. (2014) validated the dust detection using the probability of detection (POD) and false alarm rate (FAR) as functions of different values of FMF and AOT. As the dust detection algorithm developed in this study focused not only on strong dust storms over source regions but also weakened dust storms in mixed conditions of fine and coarse aerosol, for quantitative validation, we applied the low threshold for AOT (i.e., 0.2, 0.3, and 0.4) and the high threshold for FMF (i.e., 0.4, 0.5, and 0.6) to S-NPP/VIIRS (Lee et al. 2017; Sayer et al. 2018b).

Table 2 summarizes the POD and FAR with respect to the thresholds of AOT and FMF from 27 to 2019 to 29 October 2019. We calculated the POD and FAR as follows:

$P O D=\frac{D_{\text {Suomi-NPP\&GK2A }}}{D_{\text {Suomi-NPP }}}$
$F A R=1-\frac{D_{\text {Suomi-NPP\&GK2A }}}{D_{G K 2 A}}$

where $D_{S u o m i-N P P}$ and $D_{G K 2 A}$ denote the number of pixels detected as dust from S-NPP and GK2A/AMI, respectively, and $D_{\text {Suomi-NPP \& GK2A }}$ indicates the number of dust-detected pixels from S-NPP and GK2A/AMI, simultaneously. As the threshold of AOT increases, since the only pixels including a very large amount of aerosol load were selected, the POD and FAR increased simultaneously. In the cases with AOT $>0.2$, the accuracy showed that the POD (FAR) was showed from $0.439(0.082)(\mathrm{DD}>0.3$ and $\mathrm{FMF}<0.6)$ to $0.799(0.287)$ $(\mathrm{DD}>0.1$ and FMF $<0.4)$; however, for the cases with AOT $>0.4$, the POD (FAR) was from 0.544 (0.166) $(\mathrm{DD}>$ 0.3 and $F M F<0.6)$ to $0.850(0.439)(\mathrm{DD}>0.1$ and $\mathrm{FMF}<$ 0.4). On the other hand, as the threshold of FMF decreased, because only pixels with a strong dust storm in a coarse aerosol dominated condition were classified, the POD and FAR increased simultaneously. For the cases with FMF $<0.4$, the accuracy showed that the POD (FAR) was from $0.571(0.209)$ $(\mathrm{DD}>0.3$ and $\mathrm{AOT}>0.2)$ to $0.850(0.439)$ (DD $>0.1$ and AOT $>0.4)$; but, in the cases with FMF <0.6, POD (FAR) was showed from 0.439 (0.082) (DD $>0.3$ and $\mathrm{AOT}>0.2)$ to $0.737(0.271)(\mathrm{DD}>0.1$ and $\mathrm{AOT}>0.4)$. For the cases of a strong dust storm in coarse aerosol dominated conditions with FMF $<0.4$ and AOT $>0.4$, the accuracy showed that the POD (FAR) was 0.850 (0.439) (DD > 0.1); however, in the cases of a weakened dust storm in a mixture of coarse and fine aerosol with FMF $<0.6$ and AOT $>0.2$, the POD (FAR) was showed $0.667(0.100)(\mathrm{DD}>0.1)$. These results indicate that the combined dust detection algorithm of GK2A/AMI detects not only the severe dust storms but also weakened dust 

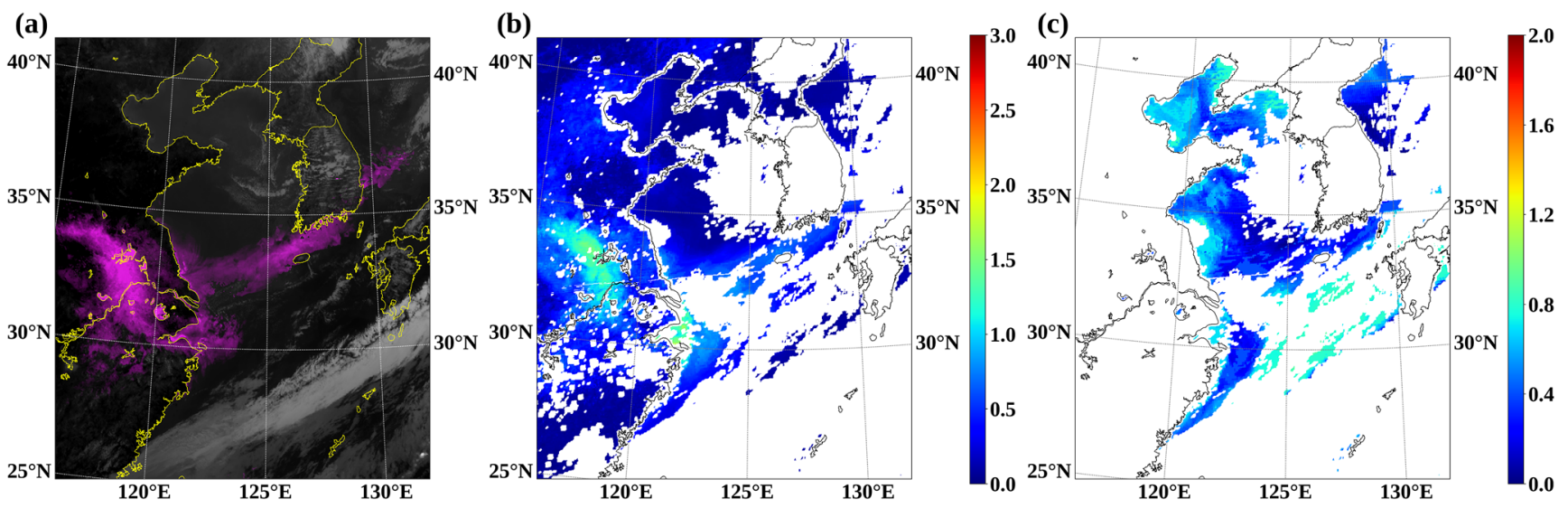

Fig. 12 (a) Derived dust detection from GK2A/AMI and (b) aerosol optical thickness (AOT) and (c) fine mode fraction (FMF) derived from S-NPP/ VIIRS observed on 29 October 2019 05:20 UTC (29 October 2019 14:20 KST)

storms over oceans with reasonably good performance. The relative high FAR with respect to POD could imply that the combined dust detection algorithm of GK2A/AMI is better at detecting potential dust pixels than S-NPP/VIIRS with respect to different thresholds of AOT and FMF.

\section{Summary and Conclusion}

It is difficult to detect dust storms using traditional IR-based methods for a variety of reasons. To reduce errors in traditional dust detection methods, and to improve the accuracy of dust detection using data from GK2A/AMI, we developed an algorithm by combining multiple dust detection methods with dust-enhanced false color imagery. To improve the accuracy of dust detection, the $C D$ parameter was derived by combining six cloud tests, and the dust detection algorithm computed the $D D$ parameter (where $C D$ parameters are embedded) by combining four dust tests adopted from previous studies. Each parameter, normalized by each empirically determined MIN and MAX, was converted from 0 (low confidence) to 1 (high confidence). To consider the diurnal variations in the IR channel and the variations in BTD properties with the surface type, we applied different MIN and MAX in the parameter calculations for the daytime and nighttime over land and sea. Furthermore, we displayed the dust detection result ( $D D$ parameter) as false color imagery. In the dust-enhanced false color imagery, we expressed the dust storm as magenta, as shown in the dust RGB imagery for forecasters.

To qualitatively evaluate the new algorithm, we used the true RGB imagery, dust RGB imagery, and AD-Net data for comparison. The study case was a huge dust event from 27 to 2019 to 29 October 2019, which originated from deserts in northern China and Mongolia and was transported to the southeastern regions. Some of the dust storm was advected to the Bohai Sea and the Yellow Sea, and the rest was transported to Shanghai and the Yangtze River Estuary. It was difficult to identify the dust storm from its source regions and areas with high SPM water. As the surface temperature changed diurnally and the dust intensity weakened, it was difficult to clearly detect dust by the single BTD methods and dust RGB imagery. Since the algorithm proposed in this study combines multiple dust and cloud tests, it retrieves the continuous $D D$ parameter and shows outstanding performance with high reliability. The combined dust detection algorithm especially improved the discontinuity of the dust RGB imagery when a weak dust storm advected to the sea, and false alarms were considerably reduced.

Table 2 Probability of detection (POD) and false alarm rate (FAR) of the combined dust detection algorithm as a function of aerosol optical thickness (AOT) and fine mode fraction (FMF)

\begin{tabular}{|c|c|c|c|c|c|c|c|c|c|}
\hline \multirow{2}{*}{$\begin{array}{l}\text { POD } \\
\text { (FAR) } \\
N=83,080\end{array}$} & \multicolumn{3}{|l|}{$\mathrm{FMF}<0.4$} & \multicolumn{3}{|l|}{$\mathrm{FMF}<0.5$} & \multicolumn{3}{|l|}{$\mathrm{FMF}<0.6$} \\
\hline & $\mathrm{AOT}>0.2$ & $\mathrm{AOT}>0.3$ & $\mathrm{AOT}>0.4$ & $\mathrm{AOT}>0.2$ & $\mathrm{AOT}>0.3$ & $\mathrm{AOT}>0.4$ & $\mathrm{AOT}>0.2$ & $\mathrm{AOT}>0.3$ & $\mathrm{AOT}>0.4$ \\
\hline $\mathrm{DD}>0.1$ & $\begin{array}{l}0.799 \\
(0.287)\end{array}$ & $\begin{array}{l}0.840 \\
(0.327)\end{array}$ & $\begin{array}{l}0.850 \\
(0.439)\end{array}$ & $\begin{array}{l}0.704 \\
(0.150)\end{array}$ & $\begin{array}{l}0.748 \\
(0.191)\end{array}$ & $\begin{array}{l}0.762 \\
(0.319)\end{array}$ & $\begin{array}{l}0.667 \\
(0.100)\end{array}$ & $\begin{array}{l}0.715 \\
(0.142)\end{array}$ & $\begin{array}{l}0.737 \\
(0.271)\end{array}$ \\
\hline $\mathrm{DD}>0.2$ & $\begin{array}{l}0.710 \\
(0.245)\end{array}$ & $\begin{array}{l}0.768 \\
(0.266)\end{array}$ & $\begin{array}{l}0.803 \\
(0.367)\end{array}$ & $\begin{array}{l}0.602 \\
(0.134)\end{array}$ & $\begin{array}{l}0.655 \\
(0.155)\end{array}$ & $\begin{array}{l}0.690 \\
(0.264)\end{array}$ & $\begin{array}{l}0.564 \\
(0.092)\end{array}$ & $\begin{array}{l}0.620 \\
(0.114)\end{array}$ & $\begin{array}{l}0.660 \\
(0.223)\end{array}$ \\
\hline $\mathrm{DD}>0.3$ & $\begin{array}{l}0.571 \\
(0.209)\end{array}$ & $\begin{array}{l}0.629 \\
(0.218)\end{array}$ & $\begin{array}{l}0.691 \\
(0.291)\end{array}$ & $\begin{array}{l}0.476 \\
(0.108)\end{array}$ & $\begin{array}{l}0.527 \\
(0.116)\end{array}$ & $\begin{array}{l}0.582 \\
(0.192)\end{array}$ & $\begin{array}{l}0.439 \\
(0.082)\end{array}$ & $\begin{array}{l}0.489 \\
(0.090)\end{array}$ & $\begin{array}{l}0.544 \\
(0.166)\end{array}$ \\
\hline
\end{tabular}


To quantitatively verify the new algorithm, we used the AOT and FMF derived from S-NPP/VIIRS. As the FMF and AOT vary according on the dust event, for quantitative validation in different dust storm conditions, we calculated the POD and FAR as a functions of different AOT values (i.e., 0.2, 0.3, and 0.4) and FMF values (i.e., 0.4, 0.5, and 0.6). In cases with AOT $>0.4$, the accuracy showed the POD from 0.544 to 0.850 , and for cases with AOT $>0.2$, the POD was showed from 0.439 to 0.799 . For severe dust cases (AOT $>0.4$ and FMF $<0.4$ ) and weakened dust cases (AOT $>0.2$ and FMF $<0.6$ ), the POD was showed from 0.667 to 0.850 . These values indicate that the new dust detection algorithm detects not only a severe dust event but also a weakened dust storm with good performance. For the FAR, relatively high values were given with each POD. These high FAR values could indicate that the combined dust detection algorithm was better at detecting potential dust pixels than S-NPP/VIIRS.

For dust storm monitoring, this study utilized $B T_{12.3}-$ $B T_{10.5}$ as DDI1 and $B T_{8.7}-B T_{10.5}$ as DDI2; these indices were developed and generally used in previous studies. However, the indices, $B T_{11.2}-B T_{10.5}$ as DDI3, and the PODI as DDI4, are not commonly used for dust storm monitoring. The traditional dust monitoring method showed low accuracy over the sea and humid regions where the sea wind advected; however, as the PODI was applied, the accuracy of dust storm monitoring increased over sea and coastal regions. In addition, the previous dust detection method could not effectively detect the weakened dust storm frequently, but as $B T_{11.2}-B T_{10.5}$ was applied to the combined dust detection algorithm, it was possible to reduce false alarms and improve the misdetection of the weakened dust storms. In particular, although GEO satellites (i.e., Himawari-8/ AHI, GOES-R/ABI, and GK2A/AMI), which were recently developed and operated, have an $11.2 \mu \mathrm{m}$ channel, which is not primarily used for dust monitoring, this study emphasizes the availability of the $11.2 \mu \mathrm{m}$ channel for dust detection, and it is expected that the results obtained in this study will assist future dust detection studies.

For dust detection under various surface properties and meteorological conditions, this study proposed a dust detection algorithm combining four dust tests and six cloud tests, which were developed in previous studies. The dust detection algorithm was developed only using remotely sensed data without prior information of external data. However, we applied an empirical threshold of each index optimized for a huge dust event. If dust event data can be further collected by GK2A/AMI, we expect that the algorithm can be improved by assessing the validity of each of the indices and it can be refined by considering seasonal variations and surface environments by setting the bounds based on the background.

Acknowledgements This research was supported by the "Development of Satellite Data Utilization and Operation Supportive Technology" of the National Meteorological Satellite Center, Korea Meteorological Administration.
Open Access This article is licensed under a Creative Commons Attribution 4.0 International License, which permits use, sharing, adaptation, distribution and reproduction in any medium or format, as long as you give appropriate credit to the original author(s) and the source, provide a link to the Creative Commons licence, and indicate if changes were made. The images or other third party material in this article are included in the article's Creative Commons licence, unless indicated otherwise in a credit line to the material. If material is not included in the article's Creative Commons licence and your intended use is not permitted by statutory regulation or exceeds the permitted use, you will need to obtain permission directly from the copyright holder. To view a copy of this licence, visit http://creativecommons.org/licenses/by/4.0/.

\section{References}

Ackerman, S.A.: Global satellite observations of negative brightness temperature differences between 11 and $6.7 \mu \mathrm{m}$. J. Atmos. Sci. 53(19), 2803-2812 (1996)

Ackerman, S.A., Strabala, K.I., Menzel, W.P., Frey, R.A., Moeller, C.C., Gumley, L.E.: Discriminating clear sky from clouds with MODIS. J. Geophys. Res. 103(D24), 32141-32157 (1998)

Ashpole, I., Washington, R.: An automated dust detection using SEVIRI: A multiyear climatology of summertime dustiness in the central and western Sahara. J. Geophys. Res. 117(D8), D08202 (2012)

Baddock, M.C., Bullard, J.E., Bryant, R.G.: Dust source identification using MODIS a comparison of techniques applied to the Lake Eyre Basin, Australia. Remote Sens. Environ. 113, 1511-1528 (2009)

Banks, J.R., Brindley, H.E., Flamant, C., Garay, M.J., Hsu, N.C., Kalashnikova, O.V., Klüsere, L., Sayer, A.M.: Intercomparison of satellite dust retrieval products over the west African Sahara during the Fennec campaign in June 2011. Remote Sens. Environ. 136, 99$116(2013)$

Byun, D., Schere, K.L.: Review of the governing equations, computational algorithms, and other components of the Models-3 Community Multiscale Air Quality (CMAQ) modeling system. Appl. Mech. Rev. 59(2), 51-77 (2006)

Chaboureau, J.-P., Tulet, P., Mari, C.: Diurnal cycle of dust and cirrus over West Africa as seen from Meteosat Second Generation satellite and a regional forecast model. Geophys. Res. Lett. 34(2), L02822 (2007)

Darmenov, A., Sokolik, I.N.: Identifying the regional thermal-IR radiative signature of mineral dust with MODIS. Geophys. Res. Lett. 32(16), L16803 (2005)

De Paepe, B., Dewitte, S.: Dust aerosol optical depth over a desert surface using the SEVIRI window channels. J. Atmos. Ocean. Technol. 26(4), 704-718 (2009)

Frey, R.A., Ackerman, S.A., Liu, Y., Strabala, K.I., Zhang, H., Key, J.R., Wang, X.: Cloud detection with MODIS. Part I Improvements in the MODIS cloud mask for collection 5. J. Atmos. Ocean. Technol. 25(7), 1057-1072 (2008)

Fuell, K.K., Guyer, B.J., Kann, D., Molthan, A.L., Elmer, N.: Next generation satellite RGB dust imagery leads to operational changes at NWS Albuquerque. J. Oper. Meteor. 4(6), 75-91 (2016)

Ganci, G., Vicari, A., Bonfiglio, S., Gallo, G., Del Negro, C.: A textonbased cloud detection algorithm for MSG-SEVIRI multispectral images. Geomat. Nat. Hazards Risk. 2(3), 279-290 (2011)

Hansell, R.A., Ou, S.C., Liou, K.N., Roskovensky, J.K., Tsay, S.C., Hsu, C., Ji, Q.: Simultaneous detection/separation of mineral dust and cirrus clouds using MODIS thermal infrared window data. Geophys. Res. Lett. 34(11), L11808 (2007)

He, Y., Yi, F.: Dust aerosols detected using a ground-based polarization lidar and CALIPSO over Wuhan (30.5 N, 114.4 E), China. Advan. Meteorol 2015, 1-18 (2015) 
Hong, S.: Detection of Asian Dust (Hwangsa) over the Yellow Sea by decomposition of unpolarized infrared reflectivity. Atmos. Environ. 43(37), 5887-5893 (2009)

Hong, J.K., Ryoo, S.-B., Kim, J., Lee, S.-S.: Prediction of Asian dust days over northern China using the KMA-ADAM2 model. Weather Forecast. 34(6), 1777-1787 (2019)

Hu, X.Q., Lu, N.M., Niu, T., Zhang, P.: Operational retrieval of Asian sand and dust storm from FY-2 C geostationary meteorological satellite and its application to real time forecast in Asia. Atmos. Chem. Phys. 8, 1649-1659 (2008)

Iino, N., Kinoshita, K., Tupper, A.C., Yano, T.: Detection of Asian dust aerosols using meteorological satellite data and suspended particulate matter concentrations. Atmos. Environ. 38(40), 6999-7008 (2004)

In, H.J., Park, S.U.: The soil particle size dependent emission parameterization for an Asian dust (Yellow Sand) observed in Korea in April 2002. Atmos. Environ. 37(33), 4625-4636 (2003)

Jones, T.A., Christopher, S.A.: MODIS derived fine mode fraction characteristics of marine, dust, and anthropogenic aerosols over the ocean, constrained by GOCART, MOPITT, and TOMS. J. Geophys. Res. 112(D22), D22204 (2007)

Jones, T.A., Christopher, S.A.: A reanalysis of MODIS fine mode fraction over ocean using OMI and daily GOCART simulations. Atmos. Chem. Phys. 11(12), 5805-5617 (2011)

Kaufman, Y.J., Koren, I., Remer, L.A., Tanré, D., Ginoux, P., Fan, S.: Dust transport and deposition observed from the Terra-Moderate Resolution Imaging Spectroradiometer (MODIS) spacecraft over the Atlantic Ocean. J. Geophys. Res. 110(D10), D10S12 (2005)

Key, J.R.: The cloud and surface parameter retrieval (CASPR) system for polar AVHRR: User's guide: Version 4.0. University of Wisconsin, Madison (2002)

Kim, J.: Transport routes and source regions of Asian dust observed in Korea during the past 40 years (1965-2004). Atmos. Environ. 42(19), 4778-4789 (2008)

Knapp, K.R., Frouin, R., Kondragunta, S., Prados, A.: Toward aerosol optical depth retrievals over land from GOES visible radiances: Determining surface reflectance. Int. J. Remote Sens. 26(18), 4097-4116 (2005)

Kurosaki, Y., Mikami, M.: Recent frequent dust events and their relation to surface wind in East Asia. Geophys. Res. Lett. 30(14), 1736 (2003)

Lee, J., Hsu, N.C., Sayer, A.M., Bettenhausen, C., Yang, P.: AERONETbased nonspherical dust optical models and effects on the VIIRS deep Blue/SOAR over water aerosol product. J. Geophys. Res. Atmos. 122(19), 10384-10401 (2017)

Lee, S.-M., Sohn, B.-J.: Retrieving the refractive index, emissivity, and surface temperature of polar sea ice from $6.9 \mathrm{GHz}$ microwave measurements: A theoretical development. J. Geophys. Res. Atmos. 120(6), 2293-2305 (2015)

Lee, S.S., Lim, Y.-K., Cho, J.H., Lee, H.C., Ryoo, S.B.: Improved dust emission reduction factor in the ADAM2 model using real-time MODIS NDVI. Atmosphere. 10(11), 702 (2019)

Legrand, M., Plana-Fattori, A., N'doumé, C.: Satellite detection of dust using the IR imagery of Meteosat 1. Infrared difference dust index. J. Geophys. Res. 106(D16), 18251-18274 (2001)

Lei, H., Wang, J.X.L.: Observed characteristics of dust storm events over the western United States using meteorological, satellite, and air quality measurements. Atmos. Chem. Phys. 14(15), 7847-7857 (2014)

Lensky, I.M., Rosenfeld, D.: Clouds-aerosols-precipitation satellite analysis tool (CAPSAT). Atmos. Chem. Phys. 8(22), 6739-6753 (2008)

Li, J., Zhang, P., Schmit, T.J., Schmetz, J., Menzel, W.P.: Quantitative monitoring of a Saharan dust event with SEVIRI on Meteosat-8. Int. J. Remote Sens. 28(10), 2181-2186 (2007)

Liou, K.: An introduction to atmospheric radiation, 2nd edn. Academic, San Diego (2002)
Liu, Y., Key, J.R., Frey, R.A., Ackerman, S.A., Menzel, W.P.: Nighttime polar cloud detection with MODIS. Remote Sens. Environ. 92(2), 181-194 (2004)

Liu, Y., Liu, R., Cheng, X.: Dust detection over desert surfaces with thermal infrared bands using dynamic reference brightness temperature differences. J. Geophys. Res. Atmos. 118(15), 8566-8584 (2013)

Miller, S.D., Bankert, R.L., Solbrig, J.E., Forsythe, J.M., Noh, Y.-J., Grasso, L.D.: A dynamic enhancement with background reduction algorithm: overview and application to satellite based dust storm detection. J. Geophys. Res. Atmos. 122(23), 12938-12959 (2017)

Miller, S.D., Grasso, L.D., Bian, Q., Kreidenweis, S.M., Dostalek, J.F., Solbrig, J.E., Bukowski, J., van den Heever, S.C., Wang, Y., Xu, X., Wang, J., Walker, A.L., Wu, T.-C., Zupanski, M., Chiu, C., Reid, J.S.: A tale of two dust storms: analysis of a complex dust event in the middle east. Atmos. Meas. Tech. 12(9), 5101-5118 (2019)

Miller, S.D., Lindsey, D.T., Seaman, C.J., Solbrig, J.E.: GeoColor: a blending technique for satellite imagery. J. Atmos. Ocean. Tech. 37(3), 429-448 (2020)

MODIS Cloud Mask Team: Discriminating clear-sky from cloud with MODIS algorithm theoretical basis document (MOD35). Available online at http://citeseerx.ist.psu.edu/viewdoc/download?doi=10.1.1. 385.7073\&rep=rep1\&type=pdf (2010). Accessed 16 Jan 2020

Moreira, N.: Dust detection: The dust RGB product. EUMETSAT online Training Library. Available online at http://www.eumetsat.int/ website/home/Data/Training/TrainingLibrary/DAT_2042669.html? lang=EN. (2011)

Park, S.S., Kim, J., Lee, J., Lee, S., Kim, J.S., Chang, L.S., Ou, S.: Combined dust detection algorithm by using MODIS infrared channels over East Asia. Remote Sens. Environ. 141, 24-39 (2014)

Park, S.U., In, H.J.: Parameterization of dust emission for the simulation of the yellow sand (Asian dust) event observed in March 2002 in Korea. J. Geophys. Res. 108(D19), 4618 (2003)

Pierangelo, C., Chedin, A., Heilliette, S., Jacquinet-Husson, N., Armante, R.: Dust altitude and infrared optical depth from AIRS. Atmos. Chem. Phys. 4(7), 1813-1822 (2004)

Roskovensky, J.K., Liou, K.N.: Differentiating airborne dust from cirrus clouds using MODIS data. Geophys. Res. Lett. 32(12), L12809 (2005)

Prata, A.J.: Observations of volcanic ash clouds in the $10-12 \mu \mathrm{m}$ window using AVHRR/2 data. Int. J. Remote Sens. 10(4-5), 751-761 (1989)

Salisbury, J.W., Eastes, J.W.: The effect of particle size and porosity on spectral contrast in the mid-infrared. Icarus. 64(3), 586-588 (1985)

Salisbury, J.W., Wald, A.: The role of volume scattering in reducing spectral contrast of reststrahlen bands in spectra of powdered minerals. Icarus. 96(1), 121-128 (1992)

Sayer, A.M., Hsu, N.C., Lee, J., Bettenhausen, C., Kim, W.V., Smirnov, A.: Satellite Ocean Aerosol Retrieval (SOAR) Algorithm Extension to S-NPP VIIRS as Part of the "Deep Blue" Aerosol Project. J. Geophys. Res. Atmos. 123(1), 380-400 (2018)

Sayer, A.M., Hsu, N.C., Lee, J., Kim, W.V., Dubovik, O., Dutcher, S.T., Huang, D., Litvinov, P., Lyapustin, A., Tackett, J.L., Winker, D.M.: Validation of SOAR VIIRS over-water aerosol retrievals and context within the global satellite aerosol data record. J. Geophys. Res. Atmos. 123(23), 13496-13526 (2018b)

Schmetz, J., Tjemkes, S.A., Gube, M., Van de Berg, L.: Monitoring deep convection and convective overshooting with METEOSAT. Adv. Space Res. 19(3), 433-441 (1997)

Schepanski, K., Tegen, I., Laurent, B., Heinold, B., Macke, A.: A new Saharan dust source activation frequency map derived from MSGSEVIRI IR-channels. Geophys. Res. Lett. 34(18), L18803 (2007)

Seinfeld, J.H., Carmichael, G.R., Arimoto, R., Conant, W.C., Brechtel, F.J., Bates, T.S., Cahill, T.A., Clarke, A.D., Doherty, S.J., Flatau, P.J., Huebert, B.J., Kim, J., Markowicz, K.M., Quinn, P.K., Russell, L.M., Russell, P.B., Shimizu, A., Shinozuka, Y., Song, C.H., Tang, 
Y.H., Uno, I., Vogelmann, A.M., Weber, R.J., Woo, J.H., Zhang, X.Y.: ACE-ASIA - Regional climatic and atmospheric chemical effects of Asian dust and pollution. Bull. Amer. Meteor. Soc. 85(3), 367-380 (2004)

Shenk, W.E., Curran, R.J.: The detection of dust storms over land and water with satellite visible and infrared measurement. Mon. Weather Rev. 102(12), 830-837 (1974)

Shimizu, A., Nishizawa, T., Jin, Y., Kim, S.-W., Wang, Z., Batdorj, D., Sugimoto, N.: Evolution of a lidar network for tropospheric aerosol detection in East Asia. Opt. Eng. 56(3), 031219 (2017)

Sohn, B.J., Lee, S.-M.: Analytical relationship between polarized reflectivities on the specular surface. Int. J. Remote Sens. 34(7), 2368-2374 (2013)

Sokolik, I.N., Toon, O.B.: Incorporation of mineralogical composition into models of the radiative properties of mineral aerosol from UV to IR wavelengths. J. Geophys. Res. Atmos. 104(D8), 9423-9444 (1999)

Sokolik, I.N.: The spectral radiative signature of wind-blown mineral dust: Implications for remote sensing in the thermal IR region. Geophys. Res. Lett. 29(24), 2154 (2002)

Sugimoto, N., Uno, I., Nishikawa, M., Shimizu, A., Matsui, I., Dong, X., Chen, Y., Quan, H.: Record heavy Asian dust in Beijing in 2002: Observations and model analysis of recent events. Geophys. Res. Lett. 30(12), 1640 (2003)

Sugimoto, N., Matsui, I., Shimizu, A., Nishizawa, T., Hara, Y., Xie, C., Uno, I., Yumimoto, K., Wang, Z., Yoon, S.-C.: Lidar network observations of troposheric aerosols. Proc. SPIE 7860, 71530A (2008)

Sugimoto, N., Hara, Y., Shimizu, A., Nishizawa, T., Matsui, I., Nishikawa, M.: Analysis of dust events in 2008 and 2009 using the lidar network, surface observations and the CFORS model. Asia-Pacific J. Atmos. Sci. 49(1), 27-39 (2013)

Sugimoto, N., Nishizawa, T., Shimizu, A., Matsui, I., Kobayashi, H.: Detection of internally mixed Asian dust with air pollution aerosols using a polarization optical particle counter and a polarizationsensitive two-wavelength lidar. J. Quant. Spectros. Radiat. Transf. 150, 107-113 (2015)

Takashima, T., Masuda, K.: Emissivities of quartz and Sahara dust powders in the infrared region $(7-17 \mu)$. Remote Sens. Environ. 23(1), 51-63 (1987)

Tan, S.-C., Wang, H.: The transport and deposition of dust and its impact on phytoplankton growth in the Yellow Sea. Atmos. Environ. 99, 491-499 (2014)

Trepte, Q., Minnis, P., Palikonda, R., Spangenberg, D., Haeffelin, M.: Improved thin cirrus and terminator cloud detection in CERES cloud mask. Proceeding of American Meteorological Society 12th Conference on Atmospheric Radiation, 10-14 July, Madison, Wisconsin, USA. (2006)
Tsedendamba, P., Dulam, J., Baba, K., Hagiwara, K., Noda, J., Kawai, K., Sumiya, G., McCarthy, C., Kai, K., Hoshino, B.: Northeast Asian Dust transport: a case study of a dust storm event from 28 March to 2 April 2012. Atmosphere. 10(2), 69 (2019)

Wald, A.E., Salisbury, J.W.: Thermal infrared directional emissivity of powdered quartz. J. Geophys. Res. 100(B12), 24665-24675 (1995)

Wald, A.E., Kaufman, Y.J., Tanre, D., Gao, B.-C.: Daytime and nighttime detection of mineral dust over desert using infrared spectral contrast. J. Geophys. Res. 103(D24), 32307-32313 (1998)

Wang, J., Liu, X., Christopher, S.A., Reid, J.S., Reid, E., Maring, H.: The effects of non-sphericity on geostationary satellite retrievals of dust aerosols. Geophys. Res. Lett. 30(24), 2293 (2003)

Wang, X., Huang, J., Ji, M., Higuchi, K.: Variability of East Asia dust events and their long-term trend. Atmos. Environ. 42(13), 3156 3165 (2008a)

Wang, Y., Yuan, Q., Shen, H., Zheng, L., Zhang, L.: Investigating multiple aerosol optical depth products from MODIS and VIIRS over Asia: Evaluation, comparison, and merging. Atmos. Environ. 230, $117548(2020)$

Wang, Y.Q., Zhang, X.Y., Gong, S.L., Zhou, C.H., Hu, X.Q., Liu, H.L., Niu, T., Yang, Y.Q.: Surface observation of sand and dust storm in East Asia and its application in CUACE/Dust. Atmos. Chem. Phys. 8(3), 545-553 (2008b)

Watson, I.M., Realmuto, V.J., Rose, W.I., Prata, A.J., Bluth, G.J.S., Gu, Y., Bader, C.E., Yu, T.: Thermal infrared remote sensing of volcanic Emissions using the Moderate Resolution Imaging Spectroradiometer. J. Volcanol. Geoth. Res. 135(1-2), 75-89 (2004)

Wenrich, M.L., Christensen, P.R.: Optical constants of minerals derived from emission spectroscopy: Application to quartz. J. Geophys. Res. 101(B7), 15921-15931 (1996)

Xu, H., Cheng, T., Xie, D., Li, J., Wu, Y., Chen, H.: Dust identification over arid and semiarid regions of Asia using AIRS thermal infrared channels. Advan. Meteorol 2014, 1-16 (2014)

Zhang, H., Ciren, P., Kondragunta, S., Laszlo, I.: Evaluation of VIIRS dust detection algorithms over land. J. Appl. Remote Sens. 12(4), 042609 (2018)

Zhou, T., Xie, H., Bi, J., Huang, Z., Huang, J., Shi, J., Zhang, B., Zhang, W.: Lidar measurements of dust aerosols during three field campaigns in 2010, 2011 and 2012 over Northwestern China. Atmosphere. 9(5), 173 (2018)

Publisher's Note Springer Nature remains neutral with regard to jurisdictional claims in published maps and institutional affiliations. 